\title{
Образование макропор в $n$-Si при анодировании в органическом электролите
}

\author{
(C) Е.В. Астрова, Н.Е. Преображенский, Г.В. Ли, С.И. Павлов \\ Физико-технический институт им. А.Ф. Иоффре Российской академии наук, \\ 194021 Санкт-Петербург, Россия \\ E-mail: east@mail.ioffe.ru
}

(Получена 26 июля 2017 г. Принята к печати 21 августа 2017 г.)

\begin{abstract}
Проведено экспериментальное исследование фотоэлектрохимического травления электронного кремния, предназначенного для солнечных элементов, в диметилформамиде, содержащем 4\% HF. Изучены морфология пор, пористость, эффективная валентность и скорость травления в зависимости от приложенного напряжения, интенсивности освещения обратной стороны образца и длительности процесса. Установлено, что закономерности анодирования $n$-Si в органическом электролите существенно отличаются от таковых в случае водных растворов. Это проявляется в том, что при напряжении выше порогового, в так называемом пробойном режиме, макропоры с вертикальными стенками начинают размножаться и интенсивно ветвиться за счет появления боковых пор. Появление вторичных пор сопровождается увеличением пористости, снижением скорости распространения пористого фронта в глубь подложки и быстрым переходом в режим электрополировки. В пробойном режиме при малых уровнях подсветки обнаружена фрактальная структура макропор, распространяющихся по определенным кристаллографическим направлениям: $\langle 100\rangle$ и, что ранее не наблюдалось, $\langle 111\rangle$. Показано, что морфологией макропор можно управлять в процессе анодирования путем перехода из одного режима в другой при изменении внешних параметров: напряжения или подсветки. Показано, что использование органического электролита позволяет получать макропористые мембраны с высокой пористостью, значительно превышающей пористость макропористых мембран, сформированных в водных электролитах при тех же условиях.
\end{abstract}

DOI: 10.21883/FTP.2018.03.45631.8695

\section{1. Введение}

Наиболее распространенным режимом анодирования $n$-Si (100) является травление при относительно низком напряжении в условиях подсветки обратной стороны пластины (back side illumination, bsi). Обычно используемые при этом водные электролиты с малым содержанием HF приводят к формированию макропор в виде цилиндрических каналов с гладкими стенками $[1,2]$. Органические электролиты чаще всего применяют для формирования макропор в $p$ - $\mathrm{Si}$, где используется присущая им высокая анизотропия травления [3-6]. Особенно малочисленны работы, посвященные исследованию травления $n$-Si в органических электролитах с освещением, в то время как они представляют определенный интерес и для понимания процесса порообразования, и с точки зрения практического применения. Существующие теории формирования макропор (см. обзор предложенных механизмов в [7]) не описывают всю сложную совокупность явлений, происходящих в процессе анодного растворения кремния, поэтому продолжают появляться новые модели травления кремния и порообразования во фторсодержащих растворах [8-10].

Первые результаты по получению макропор в органических электролитах при подсветке обратной стороны образца (n-Si org/bsi) были получены при изучении ориентационной зависимости формирования макропор еще в начале 2000-х годов. Проведенные эксперименты обнаружили преимущественное направление роста пор вдоль осей $\langle 100\rangle$ и $\langle 113\rangle$ и необычную морфологию с боковыми порами в виде длинных наклонных ветвей $[11,12]$. Для объяснения наблюдавшихся особенностей авторы привлекали модель токовых вспышек (current-burst model) и представления, основанные на существовании пор, ориентированных вдоль определенных кристаллографических осей (crysto-поры) или растущих в направлении линий тока (curro-поры) [13].

В настоящей работе проведено детальное исследование влияния света и напряжения на порообразование в $n$-Si при электрохимическом травлении в электролите, состоящем из HF и диметилформамида (ДМФ). Эксперименты проводились на кремнии, предназначенном для солнечных элементов, имеющем большую диффузионную длину неосновных носителей, необходимую для получения высокого фотоответа.

\section{2. Методика эксперимента}

Исходным материалом для анодирования служили пластины монокристаллического кремния, выращенного по методу Чохральского, легированные фосфором, с удельным сопротивлением 3 Ом·см (концентрация доноров $N_{d}=1.7 \cdot 10^{15} \mathrm{~cm}^{-3}$ ), имеющие ориентацию (100). Объемное время жизни дырок в них составляло 1 мс, что соответствует диффузионной длине $\sim 1$ мм. Пластины представляли собой квадраты размером $156 \times 156$ мм и толщиной 180 мкм, полученные резкой с помощью проволок, покрытых алмазным абразивом. Удаление нарушенного слоя и текстурирование поверхности проводилось путем обработки в горячем растворе $\mathrm{KOH}$ 


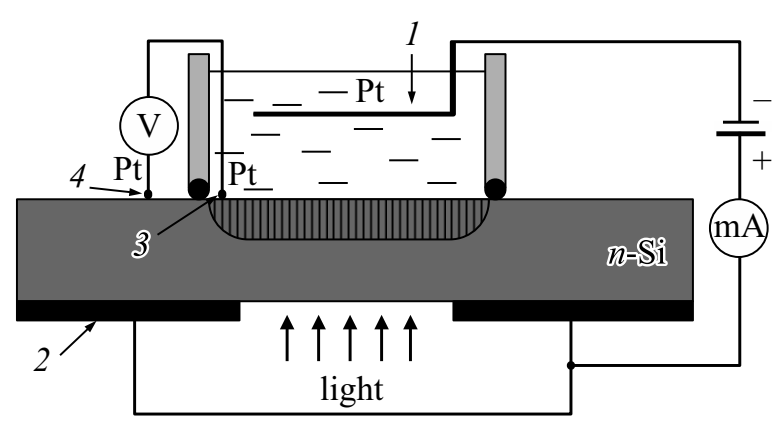

Рис. 1. Схема ячейки для фотоэлектрохимического травления.

разной концентрации и на втором этапе с добавлением изопропилового спирта. В результате на поверхности были сформированы пирамидки высотой $\sim 1.3$ мкм со средним периодом 1.4 мкм. Текстурированные пластины разделялись с помощью скрайбера на квадратные образцы $27 \times 27$ мм со сторонами вдоль направлений $\langle 110\rangle$.

Электрохимическое травление проводилось в однокамерной ячейке с четырьмя электродами (рис. 1) на установке SiPor фирмы ET\&TE при постоянной прокачке термостатируемого электролита при $22^{\circ} \mathrm{C}$.

Ток протекал через электролит и кремний между катодом 1 и металлическим контактом 2 к обратной стороне кремниевого анода. В качестве электрода сравнения использовался платиновый электрод 3, который располагался в электролите в непосредственной близости к поверхности кремниевого образца. Напряжение на границе кремний-электролит измерялось между этим псевдоэлектродом сравнения и платиновым электродом 4, касавшимся поверхности кремния вне области анодирования. Диаметр анодируемой области составлял 20 мм, диаметр окна для подсветки $D=18$ мм. Электролит состоял из 4\% (по массе) НF в ДМФ. Для освещения обратной стороны образца использовалось излучение с длиной волны $\lambda=0.88$ мкм от светодиодной матрицы, интенсивность подсветки была пропорциональна напряжению на матрице $E$. Травление велось в потенциостатическом режиме при фиксированном напряжении $U$. В каждом эксперименте регистрировались зависимости от времени $t$ тока, $I(t)$, напряжения, $U(t)$, и освещенности, $E(t)$, которые записывались в файл.

До и после анодирования образцы взвешивали и по разности полученных величин определяли массу растворенного кремния $\Delta M$. Для нахождения глубины пористого слоя $L$ образец раскалывали, и глубину измеряли с помощью оптического микроскопа. В случае, когда пористый слой отслаивался от подложки, глубину определяли с помощью толщиномера по высоте ступеньки, образовавшейся между углублением в области травления и не подвергшейся анодированию части образца. Пористость $p$ находили как

$$
p=\frac{\Delta M}{\rho_{\mathrm{Si}} L S},
$$

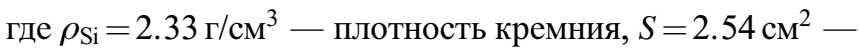
площадь освещенной области. Эффективную валент- ность $n$ определяли из закона Фарадея как отношение количества электричества $Q$ к массе растворенного $\mathrm{Si}$ :

$$
n=k Q / \Delta M,
$$

где $k=2.91 \cdot 10^{-4} \Gamma /(\mathrm{A} \cdot \mathrm{c})$. Величину $Q$ определяли с помощью численного интегрирования зависимости тока от времени. Средняя скорость травления $r$ рассчитывалась как отношение глубины пористого слоя ко времени, $r=L / t$. Морфология пор изучалась с помощью оптического микроскопа Nikon LV150 и сканирующего электронного микроскопа (SEM) марки JSM 7001F (JEOL) по изображениям поперечного сечения в плоскости (110).

\section{3. Вольт-амперная характеристика}

Вольт-амперные характеристики (ВАХ) исходного образца $n-\mathrm{Si}$, записанные при отсутствии освещения, при-

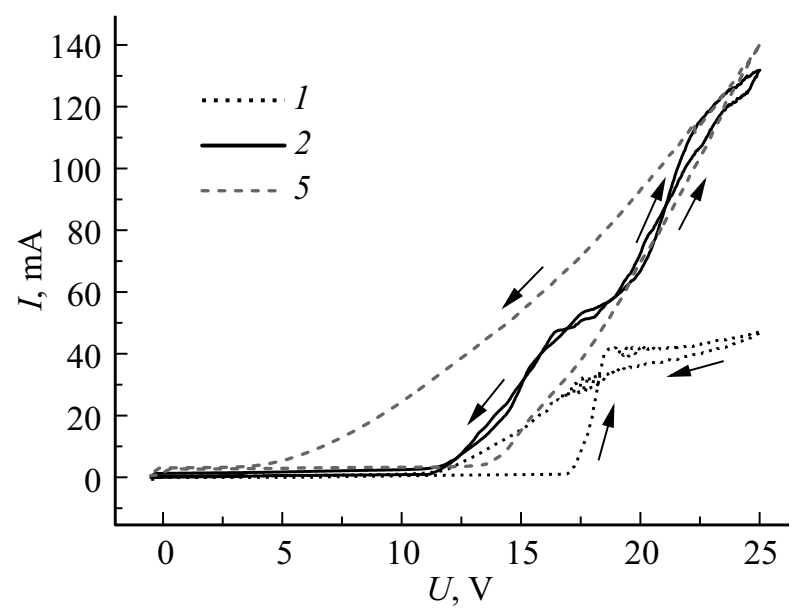

Рис. 2. Темновые BAX структуры $\mathrm{Si-электролит,} \mathrm{записан-}$ ные на исходном образце. 1,2,5 - номера циклов, стрелки - направление изменения напряжения. Скорость развертки $0.1 \mathrm{~B} /$ сек.

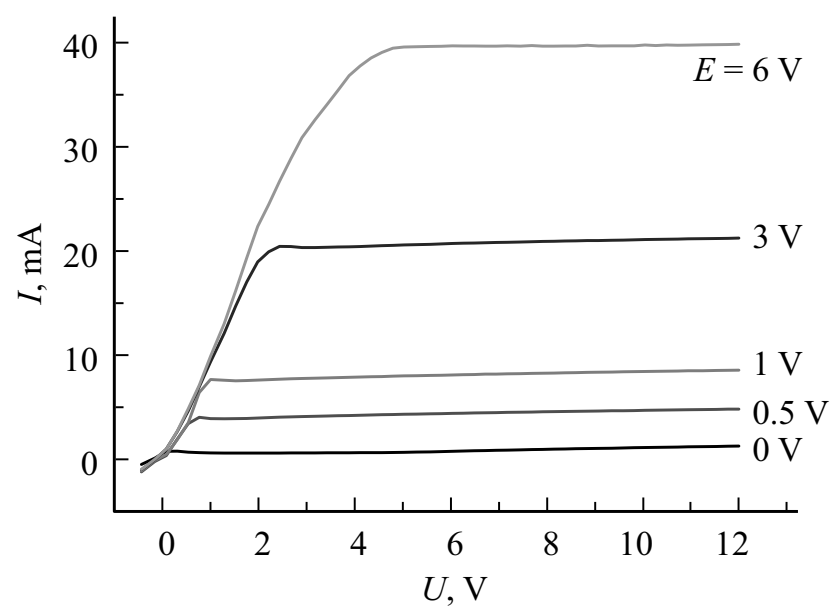

Рис. 3. Влияние интенсивности света на ВАХ структуры

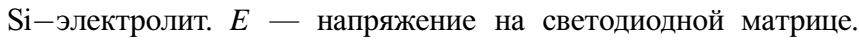
Скорость изменения напряжения $0.4 \mathrm{~B} / \mathrm{c}$. 
Таблица 1. Параметры пористых слоев, полученных в пробойном режиме $(U=10 \mathrm{~B})$ при разном освещении

\begin{tabular}{c|c|c|c|c|c|c|c|c|c}
\hline Образец & $E, \mathrm{~B}$ & $I_{0}, \mathrm{MA}$ & $I_{f}, \mathrm{мA}$ & $t$, мин & $L$, мкм & $r$, мкм/мин & $\Delta M$, мг & $n$ & $p, \%$ \\
\hline 04-04-N2 & 0 & 2 & 11 & 120 & 49.4 & 0.41 & 7.4 & 1.76 & 20.5 \\
17-04-N1 & 0.25 & 2.4 & 12.7 & 120 & 63 & 0.53 & 8.9 & 1.99 & 23.8 \\
31-03-N2 & 0.5 & 3.5 & 14 & 120 & 69 & 0.57 & 11 & 1.77 & 27 \\
17-04-N2 & 1.0 & 8.2 & 18.2 & 120 & 73.1 & 0.61 & 14.7 & 1.96 & 33.9 \\
03-04-N1 & 1.5 & 10 & 25 & 120 & 78.4 & 0.65 & 19.5 & 2.1 & 42 \\
13-04-N1 & 2 & 15 & 32 & 120 & 78.7 & 0.66 & 23.9 & 2.27 & 51.2 \\
04-04-N1 & 2.5 & 15 & 30 & 120 & 80 & 0.67 & 23.1 & 2.25 & 48.7 \\
19-04-N1 & 3 & 24.4 & 34.6 & 120 & 58.3 & 0.49 & 21.8 & 2.36 & 63.1 \\
11-04-N2 & 3.5 & 22 & 36 & 120 & 60.8 & 0.51 & 22 & 2.44 & 61 \\
12-04-N1 & 4.5 & 22 & 22 & 60 & 14 & 0.23 & 8.3 & 2.81 & 100
\end{tabular}

ведены на рис. 2. Видно, что при прямой развертке в первом цикле резкое возрастание темнового тока $I$ происходит при $U=17 \mathrm{~B}$, в то время как при обратной развертке ступенька размывается. Последующие циклы приводят к значительному темновому току уже при меньших напряжениях. Включение освещения сильно увеличивает ток. На рис. 3 показаны ВАХ в условиях разной подсветки, записанные при линейной развертке напряжения. Они имеют вид выходных характеристик транзистора, где роль эмиттера выполняет свет. ВАХ, записанные со скоростью $0.01 \mathrm{~B} / \mathrm{c}$, показали, что для исходного образца напряжение разомкнутой цепи в темноте, при $E=0 \mathrm{~B}$, составляет $U_{o c}=-400 \mathrm{мB}$. Увеличение подсветки приводит к сдвигу кривой в катодную сторону, и при $E=6 \mathrm{~B}$ оно составляет $U_{o c}=-550 \mathrm{MB}$.

\section{4. Влияние интенсивности света}

В этой серии экспериментов травление проводилось в потенциостатическом режиме при $U=10 \mathrm{~B}$ и фиксированном освещении в течение 120 мин. На рис. 4, $a$ показаны типичные зависимости тока от времени. Рост освещенности приводит к сглаживанию пика и колебаний тока, появляющихся примерно через 4-8 мин после начала травления, которые, скорее всего, связаны со стадией нуклеации. После первых 20 мин ток линейно возрастал во времени от начального значения $I_{0}$ до наибольшего значения $I_{f}$. При $E>3 \mathrm{~B}$ ток, достигнув $I_{f}=35 \mathrm{мA}$, начинал плавно уменьшаться. Обычно в таких образцах к концу процесса пористый слой частично или целиком отделялся от подложки. Наклон зависимостей $I(t)$ увеличивался по мере возрастания подсветки. Начальный и наибольший токи через ячейку были прямо пропорциональны напряжению на светодиодной матрице $E$. Это видно из зависимостей на рис. $4, b$.

В табл. 1 приведены параметры полученных слоев, а на рис. 5 и 6 - электронно-микроскопические изображения их поперечного сечения. Из рис. 5 и 6 видно, что в темноте, при $E=0 \mathrm{~B}$, формируются типичные пробойные поры, которые представляют собой тонкие извилистые каналы, заостренные книзу [2,14]. Их диаметр сильно уменьшается с глубиной от 280 до 30 нм. Нуклеация пор происходит в углублениях между
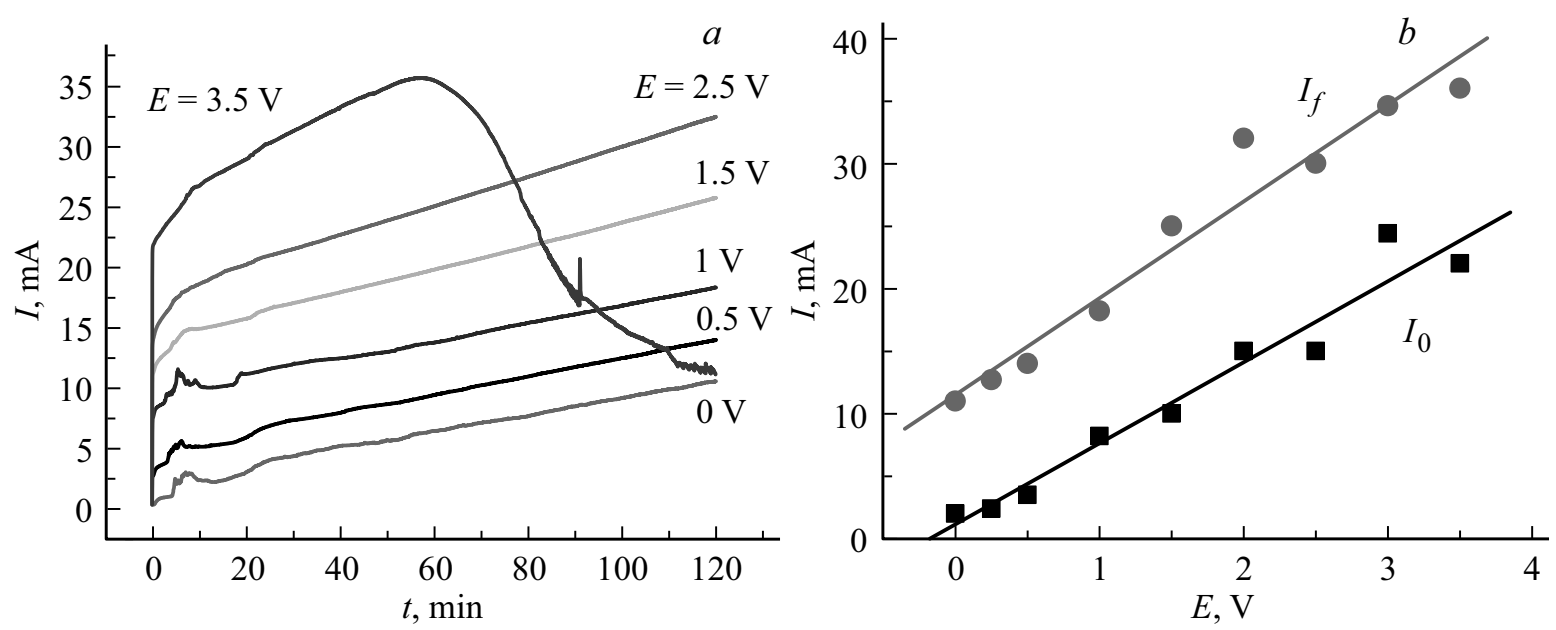

Рис. 4. Травление в режиме пробоя при $U=10 \mathrm{~B}: a-$ характерные зависимости тока травления от времени при разной подсветке; $b$ - зависимость начального $\left(I_{0}\right)$ и наибольшего $\left(I_{f}\right)$ токов от интенсивности подсветки, время травления $t=120$ мин. 


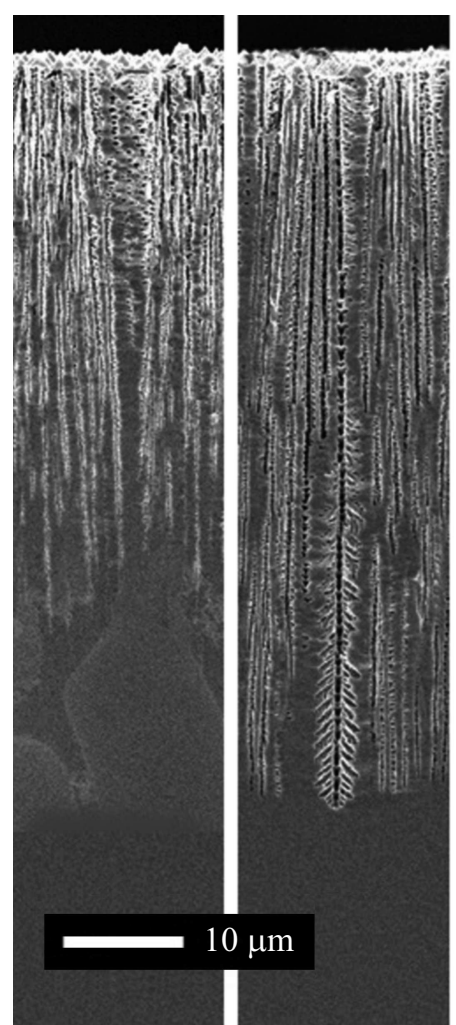

$E=0 \mathrm{~V}$

$0.25 \mathrm{~V}$

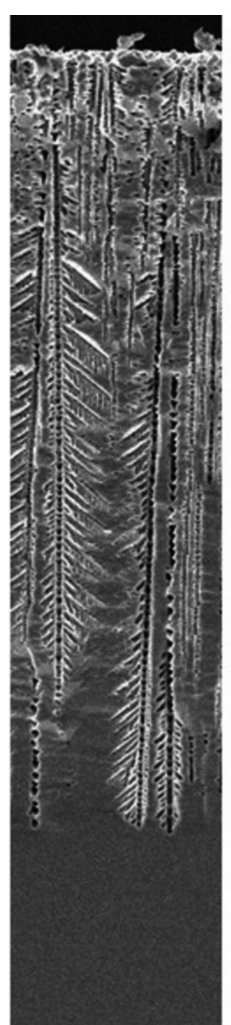

$0.5 \mathrm{~V}$

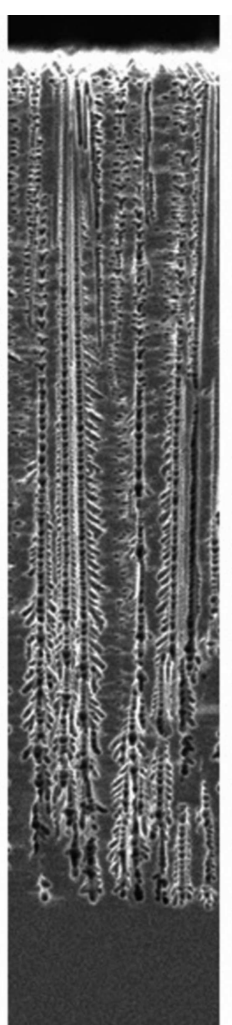

$1 \mathrm{~V}$

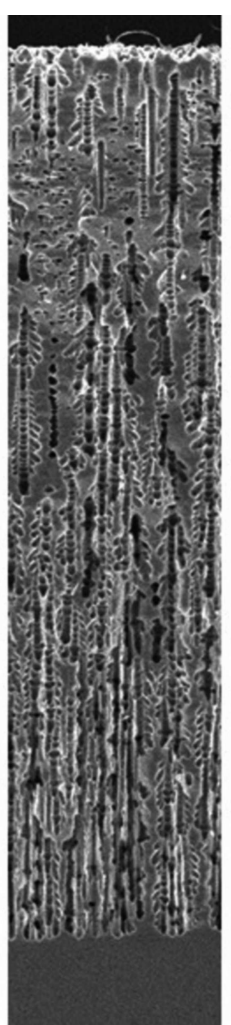

$2 \mathrm{~V}$

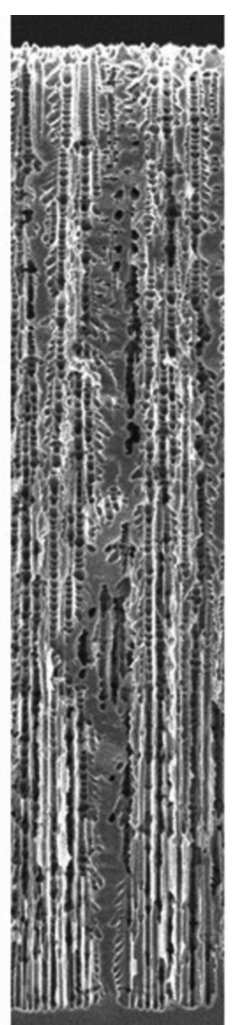

$2.5 \mathrm{~V}$

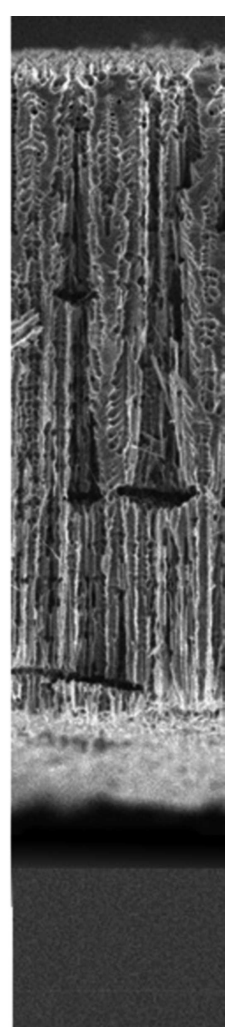

$3 \mathrm{~V}$

Рис. 5. Зависимость морфологии пористой структуры от интенсивности света (общий вид). Травление в $4 \% \mathrm{HF}$ в DMF, $U=10 \mathrm{~B}$, $t=120$ мин.
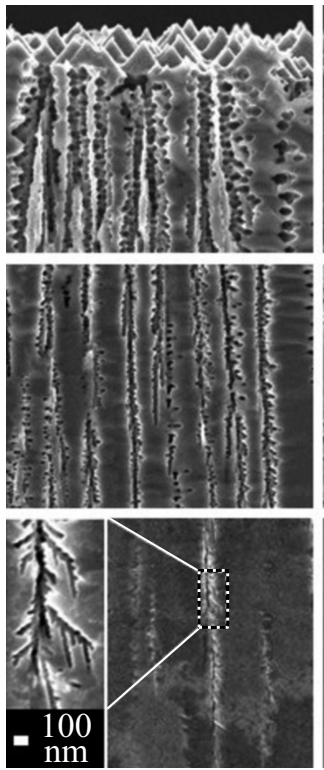

$E=0 \mathrm{~V}$
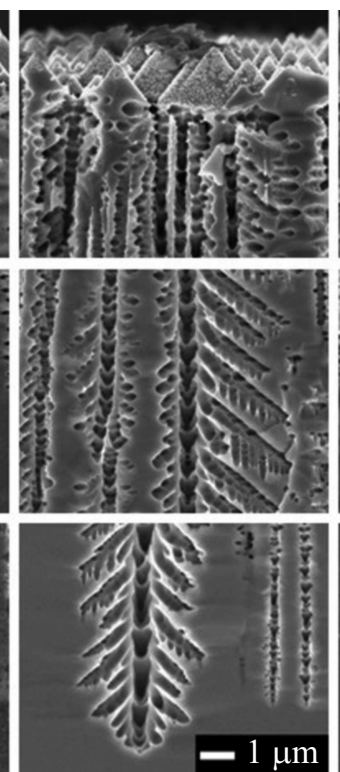

$0.25 \mathrm{~V}$
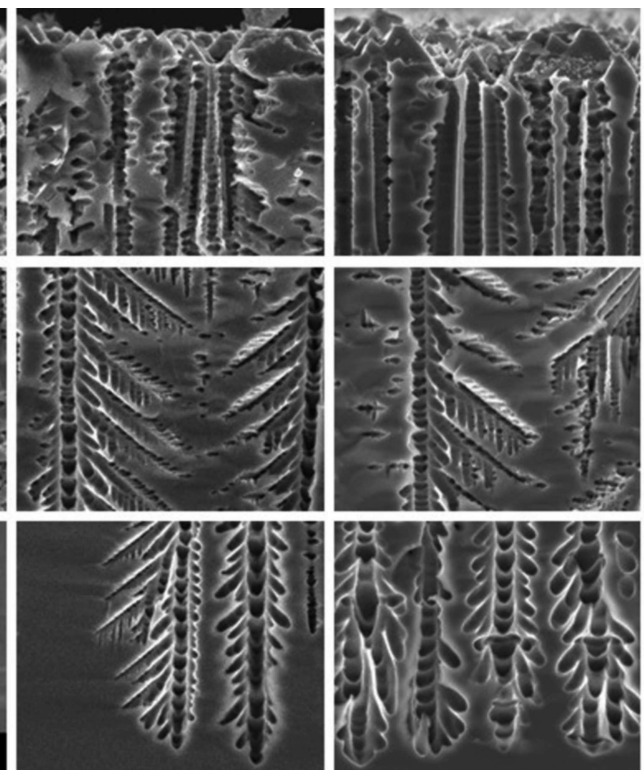

$1 \mathrm{~V}$
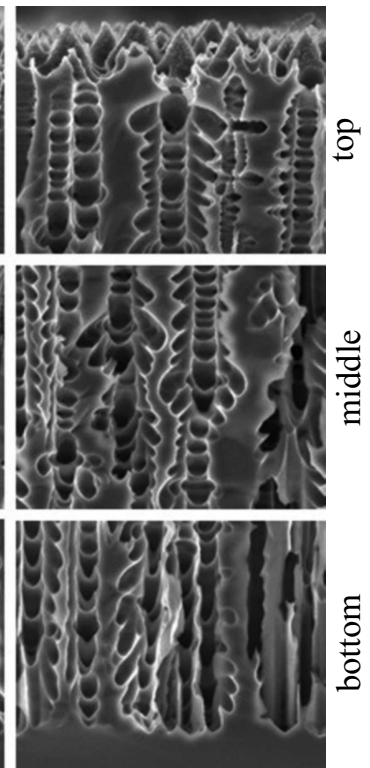

$2.5 \mathrm{~V}$

Рис. 6. Изменение морфологии пор на разной глубине в зависимости от интенсивности подсветки: увеличенное изображение структур, приведенных на рис. 5. 
Таблица 2. Режимы и параметры пористой структуры в зависимости от напряжения (анодирование при $E=2.5 \mathrm{~B}, t=90$ мин)

\begin{tabular}{c|c|c|c|c|c|c|c|c}
\hline Образец & $U, \mathrm{~B}$ & $I_{0}$ & $I_{f}$ & $L$, мкм & $r$, мкм/мин & $\Delta M$, мг & $p, \%$ & $n$ \\
\hline 18-05-N1 & 0 & 1.34 & 10 & 71.6 & 0.8 & 7.2 & 17 & 2.17 \\
17-05-N2 & 0.5 & 13.5 & 14 & 77.5 & 0.86 & 9.1 & 19.8 & 2.42 \\
17-05-N1 & 1 & 14.9 & 17.3 & 79.1 & 0.88 & 10.6 & 22.6 & 2.43 \\
16-05-N3 & 2 & 18.6 & 22 & 81.7 & 0.91 & 14 & 28.9 & 2.33 \\
16-05-N2 & 4 & 18.4 & 30 & 76.6 & 0.85 & 17.1 & 37.7 & 2.33 \\
16-05-N1 & 6 & 22 & 33 & 79.1 & 0.88 & 16.7 & 35.6 & 2.48 \\
$15-05-\mathrm{N} 2$ & 8 & 15 & 30 & 69.2 & 0.77 & 15.2 & 37 & 2.35 \\
$15-05-\mathrm{N} 1$ & 10 & 20 & 32 & 71.4 & 0.79 & 17.3 & 40.9 & 2.34 \\
$17-05-\mathrm{N} 3$ & 12 & 16 & 32 & 66.3 & 0.74 & 18.1 & 46 & 2.2
\end{tabular}

пирамидками (рис. 7). Пористый слой, сформировавшийся в темноте, не имеет плоского фронта на границе с подложкой, обладает невысокой пористостью, и его структура сильно изменяется с глубиной. Включение освещения и соответственно небольшое увеличение тока травления при $E=0.25 \mathrm{~B}$ заметно изменяет морфо-

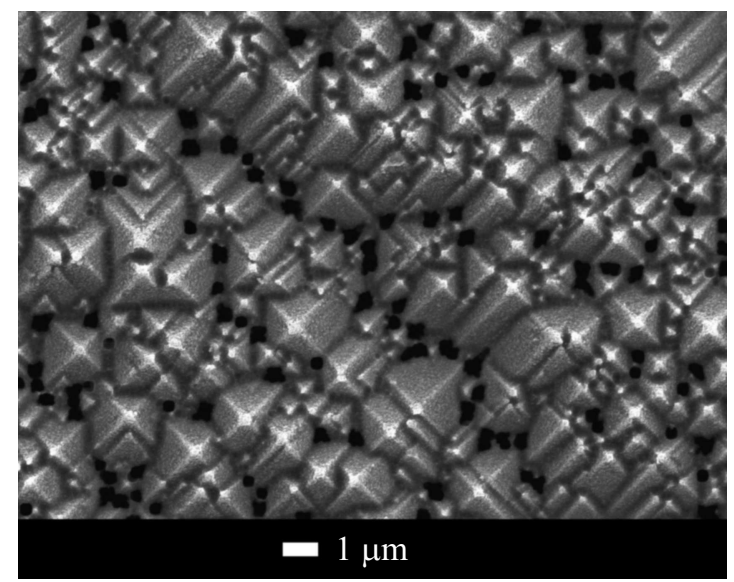

Рис. 7. Вид сверху образца 04-04-N2, травившегося в темноте.

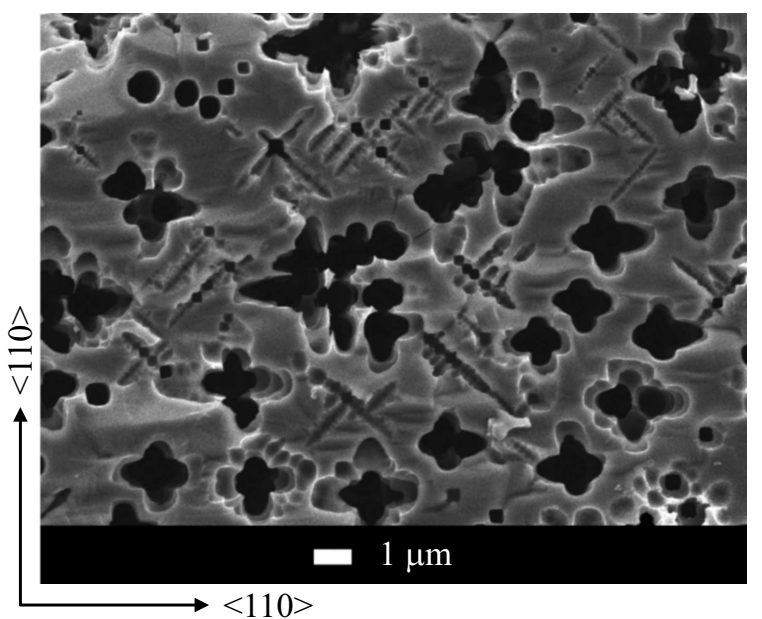

Рис. 8. Ориентация вторичных пор в плоскости (100). Вид сверху после отслоения верхней части пористого кремния. Образец 11-04-N2 $(E=3.5 \mathrm{~B}, U=10 \mathrm{~B})$. логию: диаметр каналов в средней и нижней части сильно возрастает, появляются вторичные боковые поры в виде длинных ветвей, исходящих из основных каналов и ориентированных под углом $52-54^{\circ}$ относительно вертикальной оси $\langle 100\rangle$. Ориентация боковых ветвей соответствует направлениям $\langle 111\rangle$ в плоскости скола (110). Из них в свою очередь, как сталактиты, ответвляются поры меньшего диаметра. Они направлены вдоль $\langle 100\rangle$ перпендикулярно поверхности образца. При этом сохраняются и вторичные поры, лежащие в горизонтальной плоскости и исходящие из основного канала, число которых больше в верхней части структуры. На изображениях, соответствующих $E=0.5$ и $1 \mathrm{~B}$, дополнительно появляются поры, исходящие из наклонных боковых ветвей и лежащие в горизонтальной плоскости. Дальнейшее увеличение освещенности приводит к более коротким и толстым боковым ветвям. Сечение ветвей, ориентированных перпендикулярно сколу, приводит к появлению полукруглых границ на изображении основного канала. Период этих боковых пор по мере возрастания освещения сокращается от $\sim 1$ до 0.4 мкм. Начиная с $E=3 \mathrm{~B}$, на разной глубине возникают горизонтально ориентированные пустоты (см. рис. 5), по которым пористый слой локально расслаивается. По-видимому, именно этот процесс приводит к наблюдаемому уменьшению тока от времени (рис. 4,a). На поверхности пористого слоя, оставшегося после отслоения его верхней части (рис. 8), сечение основных каналов имеет крестообразную форму, соответствующую проекции боковых ветвей на горизонтальную плоскость (100). Здесь же видны вторичные поры малого диаметра, которые выстраиваются под углом $45^{\circ}$ к сторонам креста, т.е. вдоль кристаллографических направлений $\langle 100\rangle$. Их принято называть пробойными. Интересно, что после отделения мембраны подложка перестает травиться. Эта ситуация отличается от того, что наблюдалось при травлении $p$-Si в [6]. По-видимому, происходит переход к режиму электрополировки, а не просто к увеличению диаметра макропор, как в случае отделения мембраны от $p$-Si.

На рис. 9 приведены зависимости пористости $p$, скорости травления $r$ и эффективной валентности $n$ в зависимости от интенсивности света при травлении в режиме пробоя. Пористость с увеличением $E$ плавно 

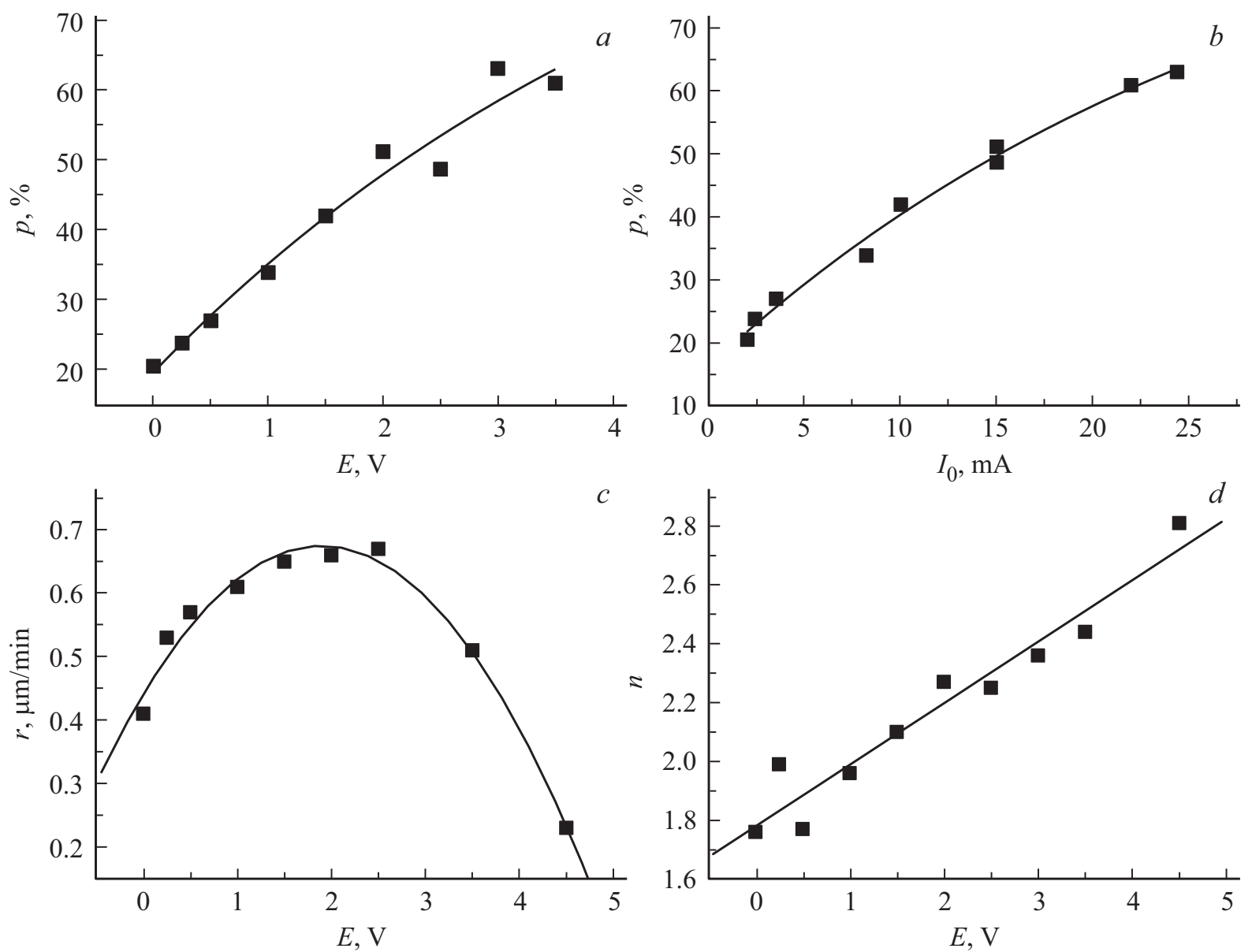

Рис. 9. Зависимость пористости $(a)$, скорости травления $(c)$, валентности $(d)$ от интенсивности света и пористости $(b)$ от начального тока $I_{0}$. Травление при напряжении $U=10 \mathrm{~B}$.

возрастает до довольно высоких значений, > 60\%. В силу того, что образцы имели некий разброс по времени жизни неосновных носителей, при одинаковой подсветке фототок в разных образцах мог иметь несколько различающиеся значения. Поэтому на зависимости пористости от начального тока, $p\left(I_{0}\right)$, наблюдался меньший разброс экспериментальных точек, чем на зависимости от освещения (см. рис. 9, $a$ и $b$ ). Из рис. 9, $d$ видно, что по мере увеличения освещенности валентность линейно увеличивается от 1.76 до 2.81. Скорость травления (рис. 9,c) имеет тенденцию к насыщению вплоть до $E=2.5$ В. При бо́льших интенсивностях света толщина и рассчитанная из нее скорость резко снижаются, так как через определенное время после начала процесса происходит расслоение пористого слоя, а затем и полное отделение мембраны от подложки. При $E=4.5 \mathrm{~B}$ наблюдается электрополировка, которая начинается уже с первых минут травления.

\section{5. Зависимость от напряжения}

Для изучения влияния напряжения была выбрана постоянная подсветка, соответствующая $E=2.5 \mathrm{~B}$, и время травления $t=90$ мин, когда на зависимости $I(t)$ еще нет спадающего участка и расслоение не происходит. В табл. 2 приводятся результаты этой серии экспериментов, включающей процесс при нулевом смещении, когда протекающий фототок является током короткого замыкания.

Из рис. 10 и 11 видно, что при малых напряжениях смещения поры имеют цилиндрическую форму, т.е. имеют вид нормальных макропор, которые будем называть фотопорами. Однако они проявляют неустойчивость, приводящую к образованию вторичных пор, и на их вертикальных стенках можно видеть появление коротких горизонтальных ответвлений в направлении $\langle 100\rangle$. Основные изменения морфологии происходят при напряжениях, бо́льших $U=2$ В. При 4 В в верхней части слоя появляются горизонтальные пробойные поры, а основные каналы в средней по глубине части начинают ветвиться. Дно каналов при этом еще сохраняет форму, характерную для фотопор. Еще бо́льшие напряжения $(U>6 \mathrm{~B})$ приводят к увеличению плотности каналов и снижению их диаметра, что способствует уменьшению длины наклонных ветвей. Идущие сверху каналы размножаются, образуя плотные скопления более тонких вторичных пор, причем на краях этих скоплений обычно 


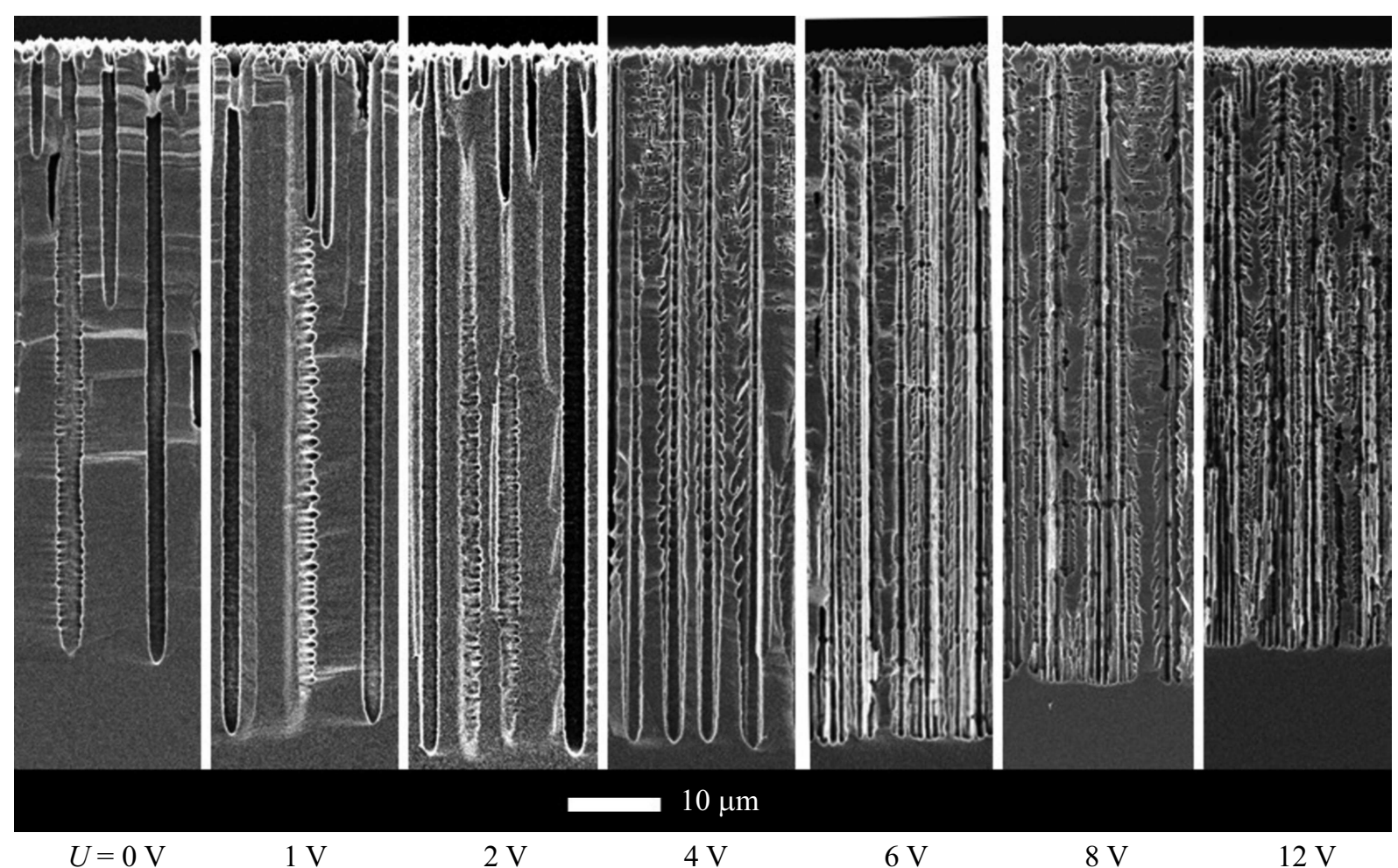

Рис. 10. Общий вид пор, образующихся при разном напряжении и фиксированной подсветке с $E=2.5 \mathrm{~B}$.

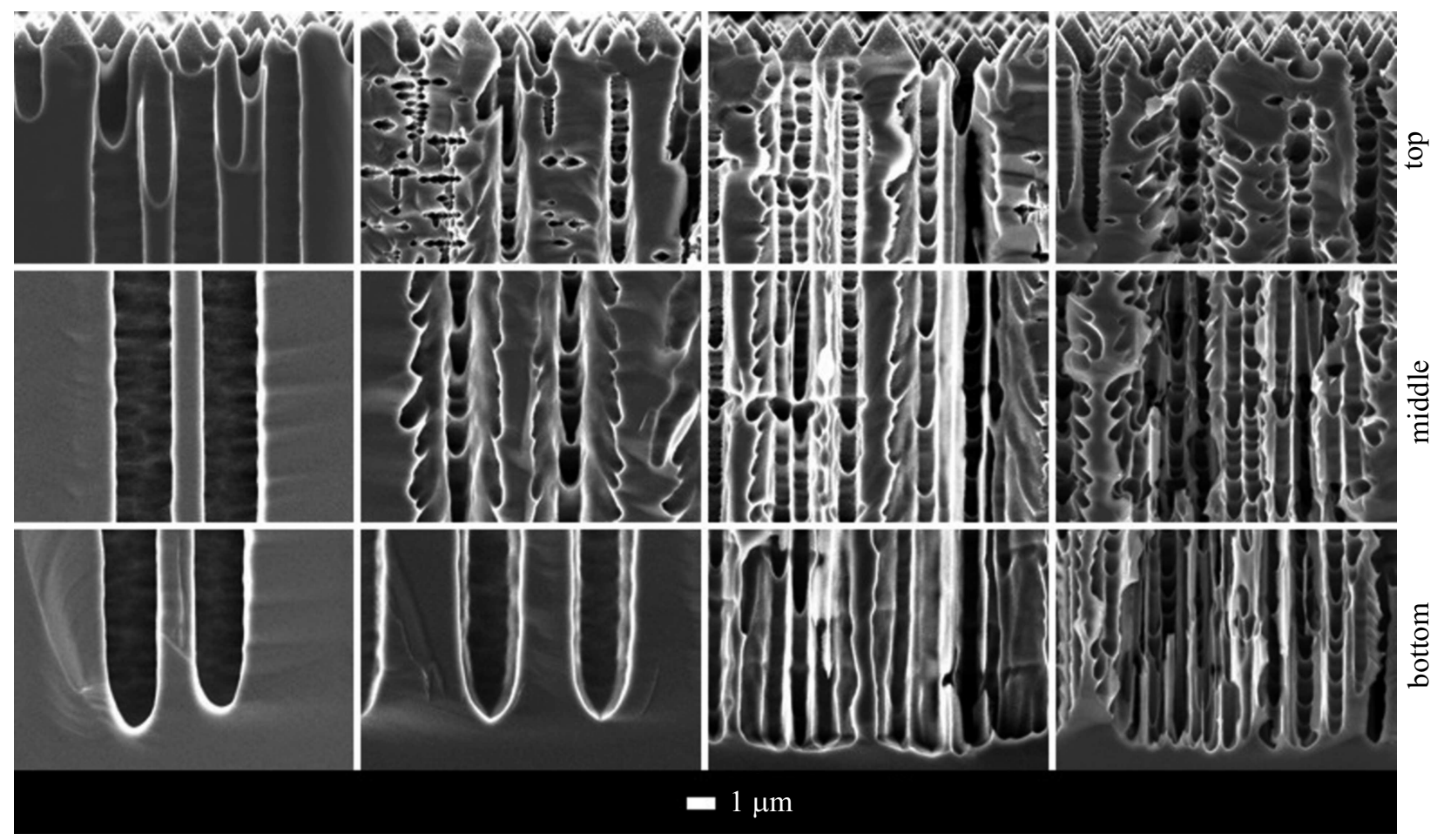

$$
U=2 \mathrm{~V}
$$

$4 \mathrm{~V}$

$6 \mathrm{~V}$

$12 \mathrm{~V}$

Рис. 11. Изменение морфологии пор на разной глубине в зависимости от напряжения: увеличенное изображение структур, показанных на рис. 10. 

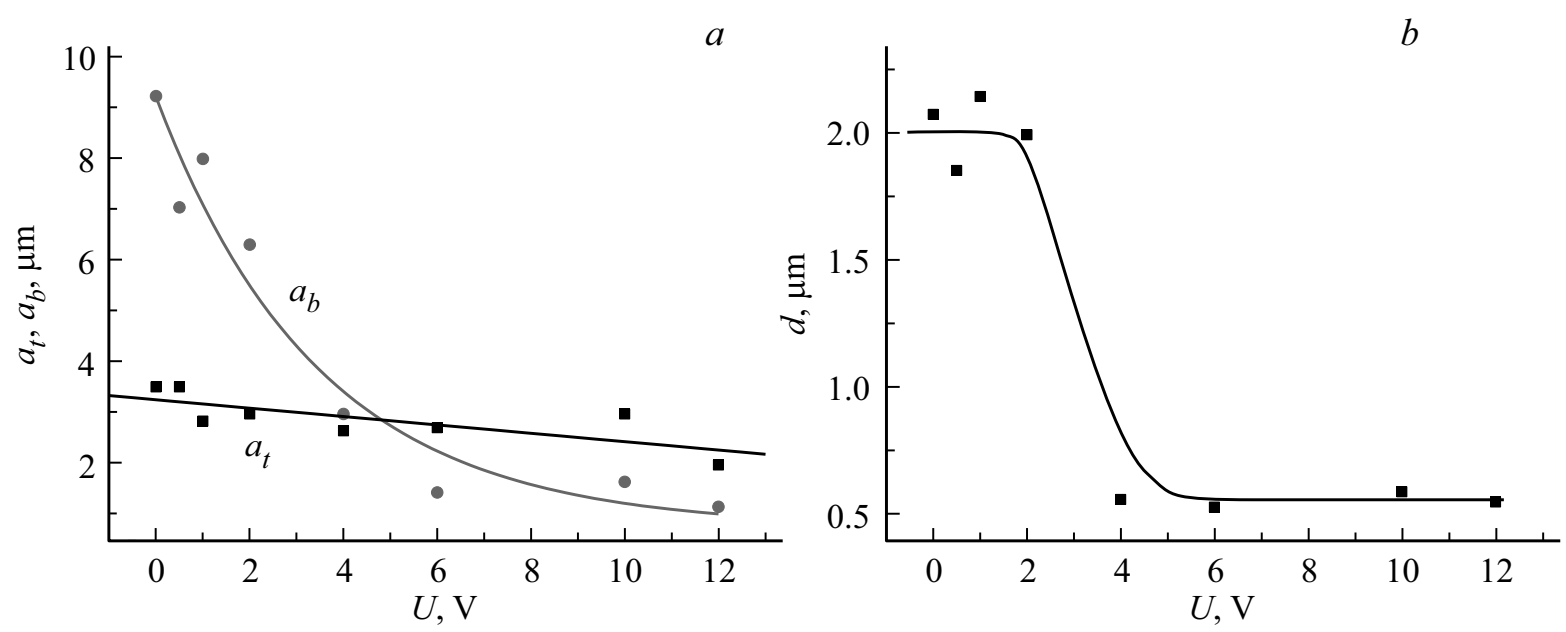

Рис. 12. Зависимости от напряжения: $a-$ средние расстояния между каналами в верхней $\left(a_{t}\right)$ и нижней $\left(a_{b}\right)$ частях пористого слоя; $b$ - диаметр каналов $d$ в средней по глубине части пористого слоя. Травление осуществлялось при постоянной подсветке с $E=2.5$ В в течение 90 мин.
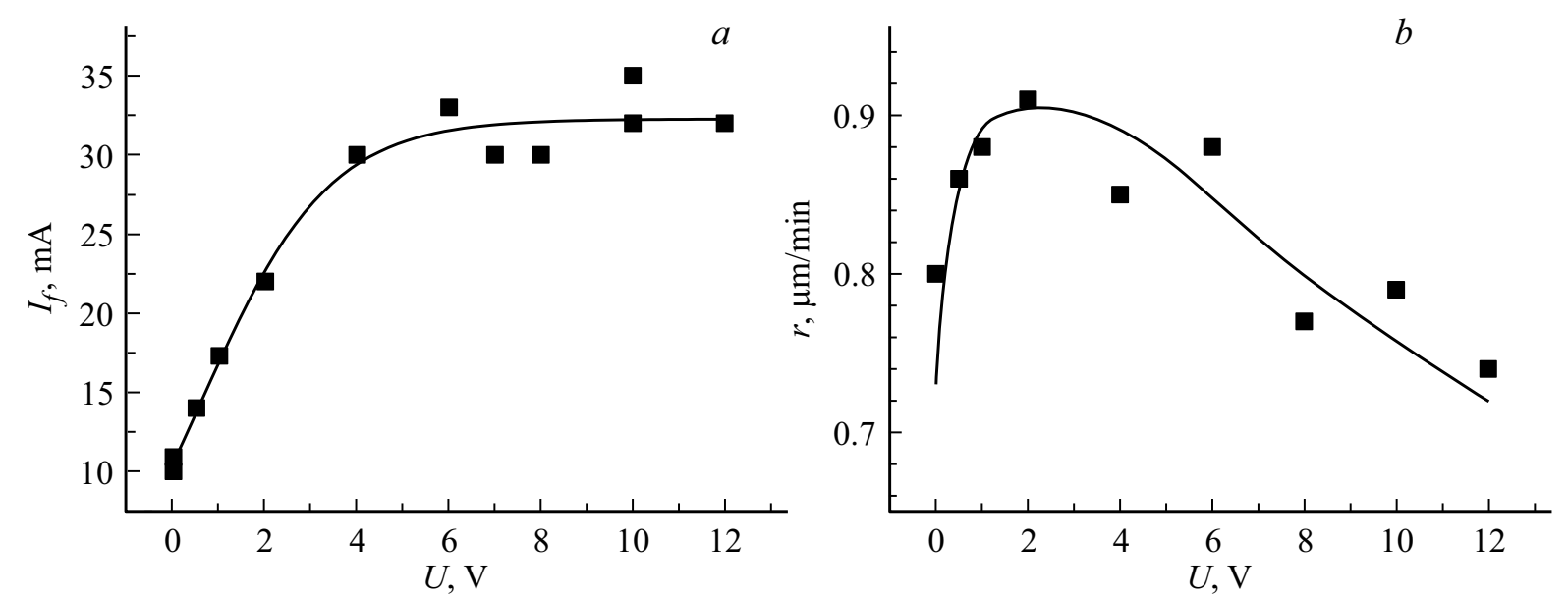

Рис. 13. Зависимости тока $I_{f}(a)$ и скорости травления $(b)$ от напряжения при травлении с подсветкой $E=2.5 \mathrm{~B}$ в течение 90 мин.

имеются боковые ветви. В результате пористый слой приобретает волнистый фронт. При еще более высоких напряжениях фронт немного выравнивается, а глубина пористого слоя снижается.

На рис. 12, а построена зависимость от напряжения среднего расстояния между каналами в верхней и нижней частях пористого слоя. Видно, что плотность пор внизу увеличивается в 9 раз при повышении напряжения от 0 до 12 В. Плотность пор в верхней части при этом возрастает не так сильно: в 1.76 раза. На рис. 12, $b$ приведена зависимость от напряжения усредненного диаметра вертикальных каналов, измеренного в средней по высоте области пор. Образовавшиеся в режиме фотопор каналы имеют диаметр $d \approx 2$ мкм. В диапазоне между $U=2$ и 4В происходит переход в пробойный режим, сопровождающийся изменением морфологии. При этом резко, почти в 4 раза, уменьшается диаметр вертикальных каналов.
На рис. 13, $а$ построена зависимость $I_{f}$ от напряжения, которая аналогична ВАХ, показанной на рис. 3. При напряжениях $U>4$ В ток насыщается.

Из рис. 13, $b$ видно, что скорость травления в диапазоне до 2 В возрастает, а затем уменьшается. Положение максимума на зависимости $r(U)$ коррелирует с изменениями в морфологии пор, когда при $U=4 \mathrm{~B}$ фотопоры преобразуются в поры с ветвями (рис. 10 и 11). Пористость увеличивается по мере увеличения напряжения и соответственно тока $I_{f}$ (рис. 14,a). Зависимость пористости от тока близка к линейной. Валентность, в отличие от серии экспериментов с переменным освещением, меняется мало, обнаруживая тенденцию к снижению $n\left(I_{f}\right)$ (рис. 14,b).

Следующая серия экспериментов по влиянию напряжения смещения проводилась при большем освещении, $E=4.5$ В. Здесь отделение пористого слоя от подложки происходило при всех приложенных напряжениях кроме 

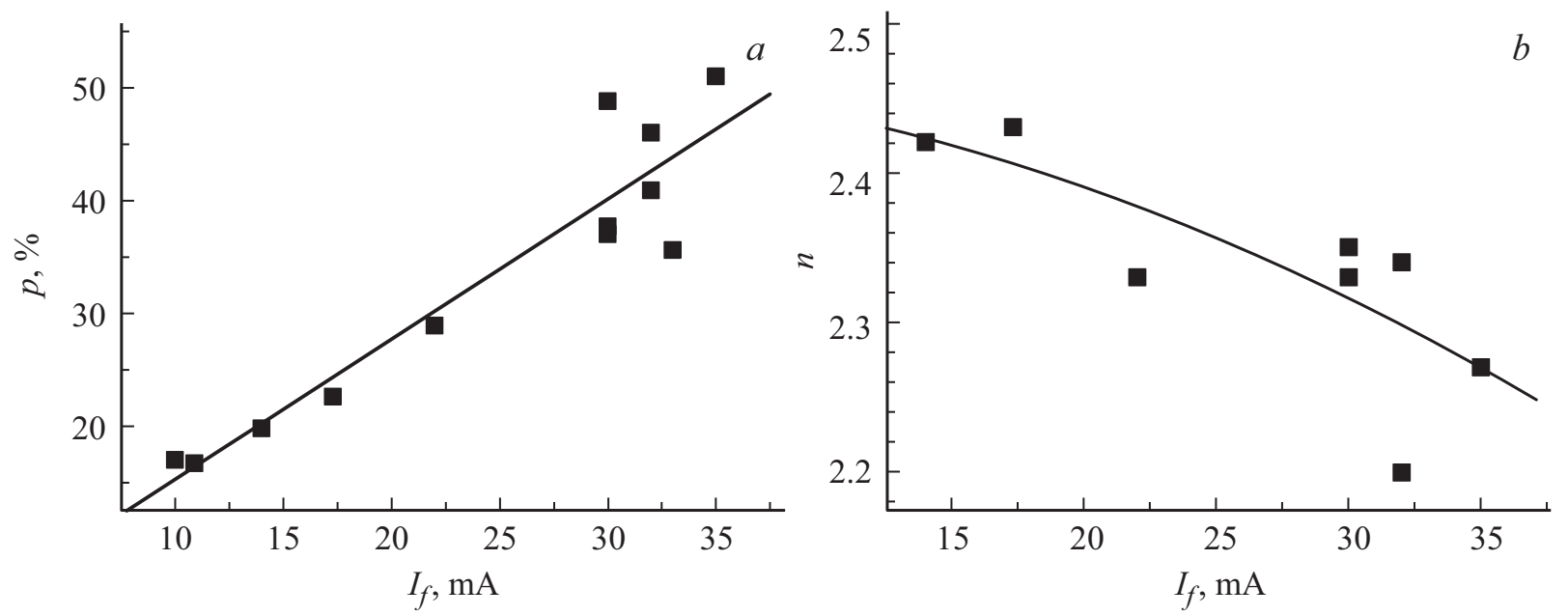

Рис. 14. Зависимости пористости $(a)$ и эффективной валентности $(b)$ от тока $I_{f}$ при травлении с подсветкой $E=2.5 \mathrm{~B}$ в течение 90 мин при разном смещении.

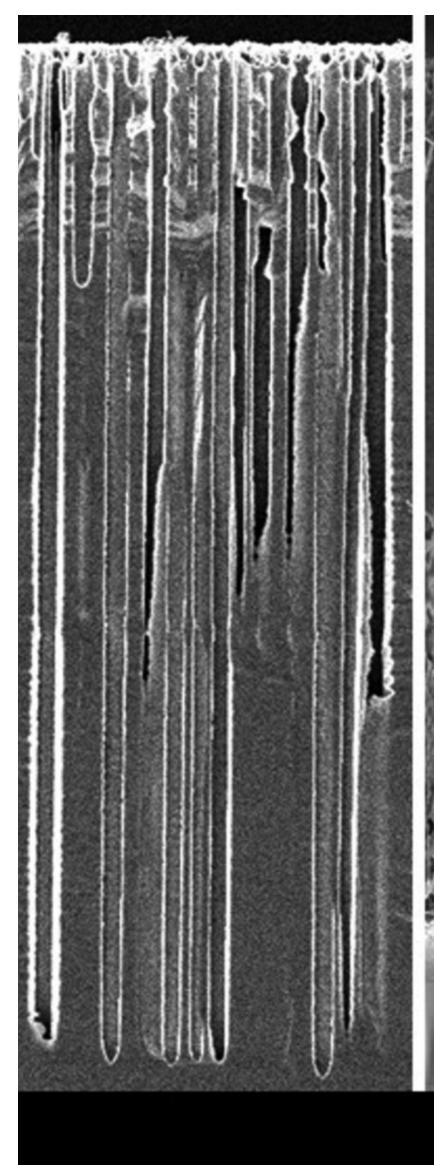

$$
U=1 \mathrm{~V}
$$
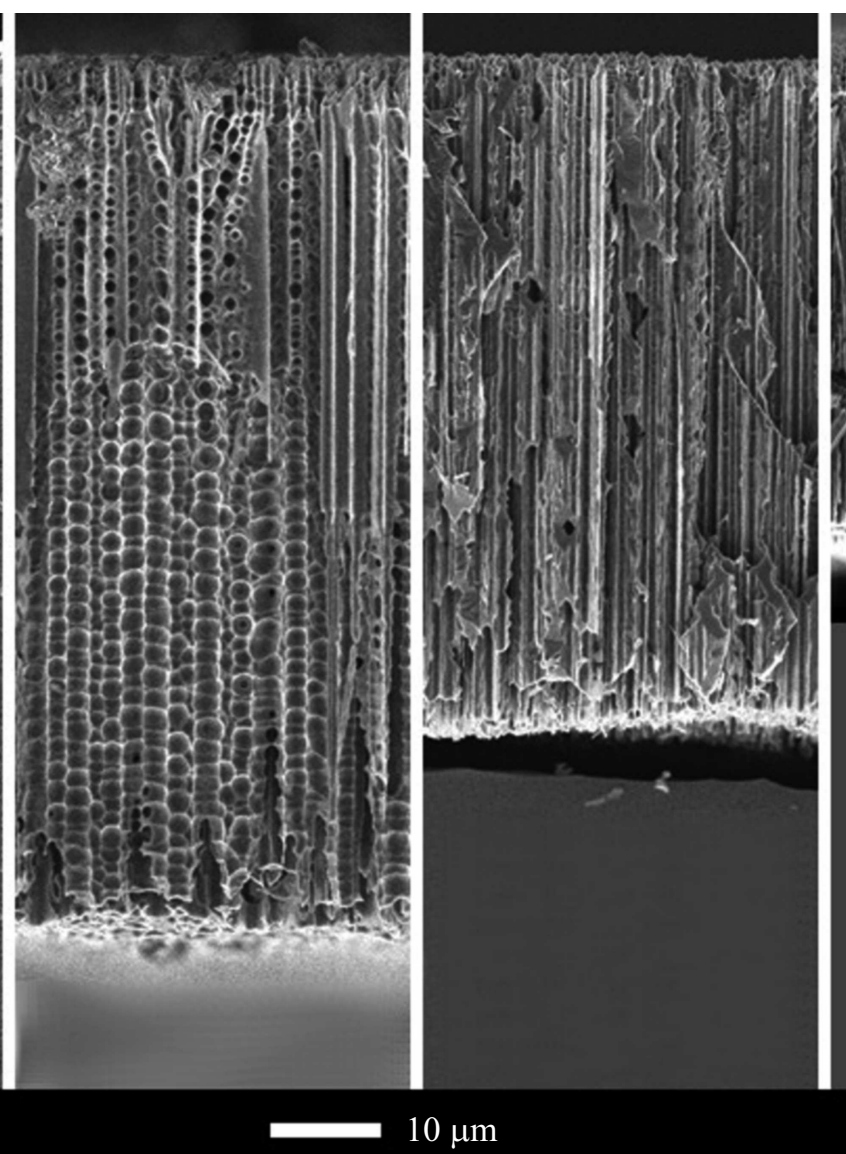

$4 \mathrm{~V}$

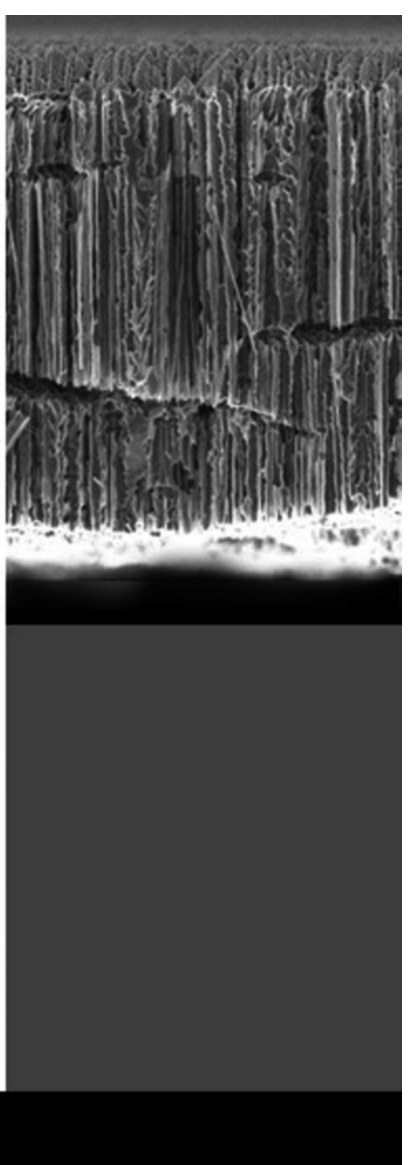

$7 \mathrm{~V}$

Рис. 15. Поперечное сечение образцов, подвергшихся электрохимическому травлению при постоянном освещении с $E=4.5 \mathrm{~B}$, при разном смещении, в течение 120 мин. 
Таблица 3. Влияние напряжения на травление при постоянной подсветке, $E=4.5 \mathrm{~B}$

\begin{tabular}{c|c|c|c|c|c|c|c|c|c|c}
\hline Образец & $U, \mathrm{~B}$ & $t$, мин & $I_{0}, \mathrm{MA}$ & $I_{f}, \mathrm{MA}$ & $L$, мкм & $r$, мкм/мин & $\Delta M$, мГ & $p, \%$ & $\begin{array}{c}\text { Время до начала } \\
\text { отделения } t_{\text {off, мин }}\end{array}$ \\
\hline 13-04-17N2 & 1 & 120 & 29 & 27 & 98 & 0.82 & 23.6 & 40.2 & $>120$ \\
$21-04-17 \mathrm{~N} 1$ & 2.5 & 120 & 36.2 & 40 & 86.2 & 0.72 & 26.7 & 55.3 & 2.44 \\
$14-04-17 \mathrm{~N} 1$ & 4 & 120 & 38 & 45 & 66 & 0.55 & 23 & 58.8 & 50 \\
$21-04-17 \mathrm{~N} 2$ & 7 & 120 & 28 & 38 & 48 & 0.4 & 17.9 & 62.9 & 35 \\
$12-04-17 \mathrm{~N} 1$ & 10 & 60 & 22 & 22 & 14 & 0.23 & 8.3 & 100 & 2.79 \\
& & & & & & & & & 2.54 \\
& & & & & & &
\end{tabular}

$U=1$ В. Временна́я зависимость тока в каждом из этих процессов имела падающий участок, такой же, как на рис. $4, a$ для $E=3.5$ В. Чем выше было напряжение, тем раньше начиналось падение тока, указывающее на расслоение и отделение пористого слоя. В табл. 3 указано на какой минуте от начала травления это происходило.

На рис. 15 показана морфология пор, сформировавшихся при подсветке с $E=4.5 \mathrm{~B}$ при разном напряжении. Видно, что увеличение интенсивности света позволяет при малом смещении $U=1 \mathrm{~B}$ получить фотопоры с довольно гладкими вертикальными стенками. Их число с глубиной уменьшается за счет вымирания. Это известное явление связано с тем, что навязанная плотность затравочных центров (углублений на текстурированной поверхности) не соответствует удельному сопротивлению материала. В соответствии с моделью Лемана [2] в режиме фотопор плотность самоорганизующихся каналов такова, что стенки между ними обеднены свободными носителями заряда из-за перекрытия областей объемного заряда. Поэтому период формирующихся макропор определяется удельным сопротивлением $n$-Si. Средний период затравочных центров в наших образцах 1.4 мкм, в то время как, согласно мнемоническому правилу, он должен составлять $2 \sqrt{\rho}=3.4$ мкм $(\rho-$ удельное сопротивление в Ом·см) [15]. При $U=2.5$ В в стенках основных каналов появляются горизонтально ориентированные поры и на 75-й минуте процесса начинается отделение от подложки. При $U=4 \mathrm{~B}$, в отличие от более слабой подсветки с $E=2.5 \mathrm{~B}$, интенсивного ветвления не наблюдается, поры направлены преимущественно вертикально, что должно быть связано с более высокой плотностью основных каналов. Отделение от подложки начинается раньше, чем при $U=2.5 \mathrm{~B}$, при $t_{\text {off }}=50$ мин. Напряжению $U=7$ В соответствует пористая структура с областями горизонтального расслоения. Отделение начинается еще раньше $\left(t_{\text {off }}=35\right.$ мин $)$ и приводит к еще более тонкой мембране.

На рис. 16 сравниваются зависимости от напряжения при двух разных подсветках. В обоих случаях на зависимости пористости от напряжения (рис. 16,a) характер кривой изменяется начиная с $U=2.5-4 \mathrm{~B}$, что коррелирует с трансформацией пористой структуры (появлением вторичных пор). Средняя скорость травления для подсветки с $E=2.5 \mathrm{~B}$ до $U=2$ В возрастает, а затем, при бо́льших напряжениях, начинает падать, в то
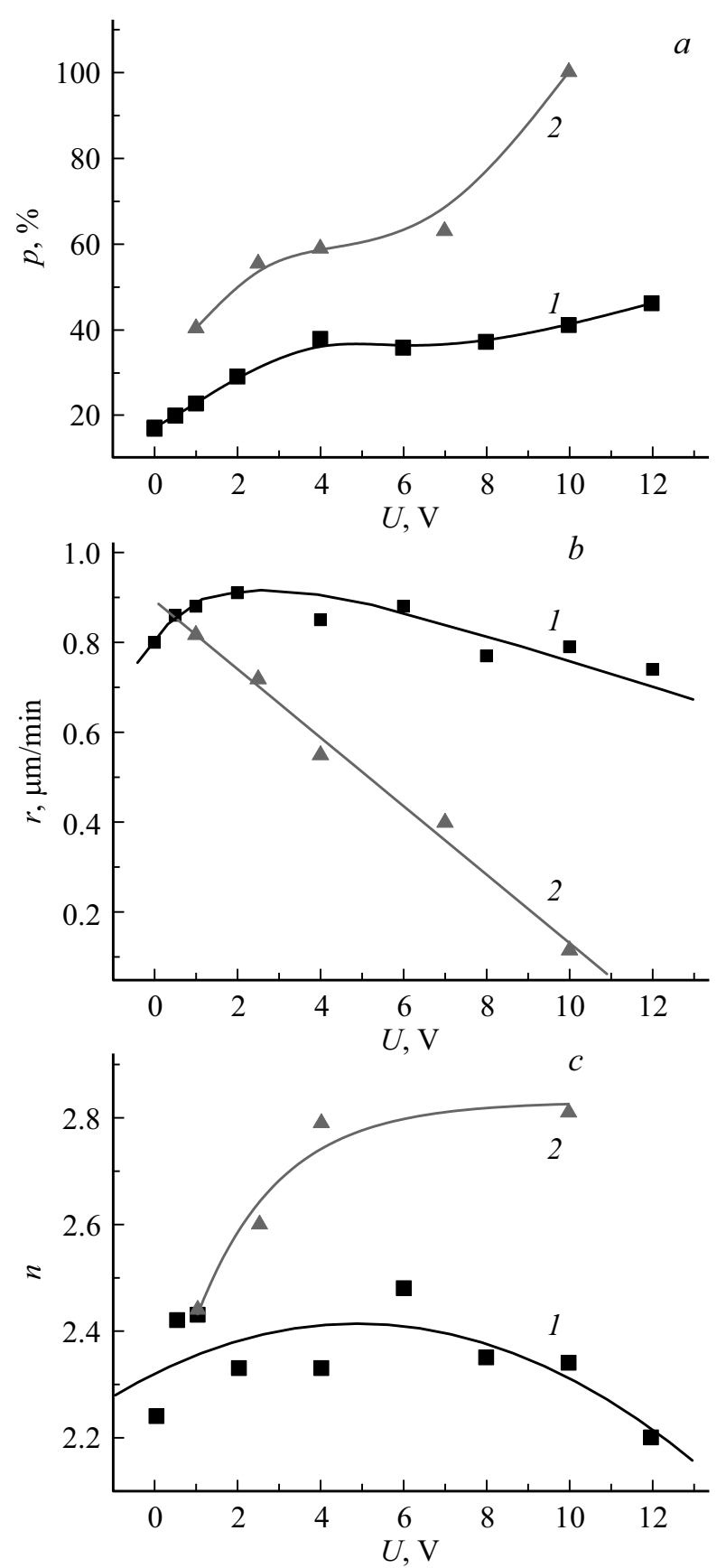

Рис. 16. Сравнение зависимостей пористости $(a)$, средней скорости травления $(b)$ и эффективной валентности $(c)$ от напряжения при разной интенсивности подсветки: $1-E=2.5 \mathrm{~B}$, $t=90$ мин; $2-E=4.5 \mathrm{~B}, t=120$ мин. 
Таблица 4. Зависимость $p, r$ и $n$ от напряжения (травление в темноте в течение 120 мин)

\begin{tabular}{l|r|c|c|c|c|c|c|c}
\hline Образец & $\begin{array}{c}U, \\
\mathrm{~B}\end{array}$ & $\begin{array}{c}\Delta M, \\
\text { мг }\end{array}$ & $\begin{array}{c}L, \\
\text { мкм }\end{array}$ & $\begin{array}{c}p, \\
\%\end{array}$ & $\begin{array}{c}r, \\
\text { мкм/мин }\end{array}$ & $n$ & $\begin{array}{c}I_{0}, \\
\mathrm{MA}\end{array}$ & $\begin{array}{c}I_{f}, \\
\mathrm{MA}\end{array}$ \\
\hline 23-06-N1 & 1 & 2.2 & 36.8 & 8.2 & 0.31 & 2.12 & 0.34 & 4.65 \\
22-06-N1 & 4 & 3.8 & 44.9 & 11.6 & 0.37 & 1.77 & 0.32 & 6.36 \\
04-04-N2 & 10 & 7.4 & 49.4 & 20.5 & 0.41 & 1.76 & 0.35 & 10.56
\end{tabular}

Таблица 5. Влияние времени травления на параметры макропористых структур

\begin{tabular}{c|c|c|c|c|c|c}
\hline Образец & $t$, мин & $E, \mathrm{~B}$ & $U, \mathrm{~B}$ & $p, \%$ & $r$, мкм/мин & $n$ \\
\hline 15-05-N1 & 90 & 2.5 & 10 & 40.9 & 0.79 & 2.34 \\
04-04-N1 & 120 & 2.5 & 10 & 48.7 & 0.67 & 2.25
\end{tabular}

Таблица 6. Серия экспериментов с переменным временем травления для режима пробоя, $U=12 \mathrm{~B}, E=2.5 \mathrm{~B}$

\begin{tabular}{c|c|c|c|c|c|c}
\hline Образец & $t$, мин & $\Delta M$, мг & $L$, мкм & $p, \%$ & $r$, мкм/мин & $n$ \\
\hline 30-05-N1 & 15 & 2.6 & 17.1 & 25.6 & 1.14 & 2.55 \\
30-05-N2 & 30 & 5.4 & 30.7 & 29.7 & 1.02 & 2.55 \\
30-05-N3 & 45 & 8.1 & 41.8 & 32.7 & 0.93 & 2.49 \\
30-05-N4 & 60 & 11.4 & 50.8 & 37.8 & 0.85 & 2.31 \\
31-05-N1 & 75 & 13.2 & 57.9 & 38.5 & 0.77 & 2.49 \\
17-05-N3 & 90 & 18.1 & 66.3 & 46.0 & 0.74 & 2.20
\end{tabular}

Таблица 7. Серия экспериментов с переменным временем травления для режима фотопор, $U=1 \mathrm{~B}, E=4.5 \mathrm{~B}$

\begin{tabular}{c|r|r|c|c|c|c}
\hline Образец & $t$, мин & $\Delta M$, мг & $L$, мкм & $p, \%$ & $r$, мкм/мин & $n$ \\
\hline 05-06-N3 & 20 & 3.7 & 20 & 31.2 & 1.00 & 2.39 \\
05-06-N2 & 40 & 7.2 & 38.9 & 31.2 & 0.97 & 2.49 \\
05-06-N1 & 60 & 11.6 & 58.6 & 33.4 & 0.98 & 2.43 \\
02-06-N2 & 80 & 14.4 & 71.5 & 34.0 & 0.89 & 2.49 \\
02-06-N1 & 100 & 18.5 & 83 & 37.6 & 0.83 & 2.42 \\
01-06-N1 & 120 & 22 & 101.3 & 36.6 & 0.84 & 2.43
\end{tabular}

время как для большей подсветки, $E=4.5 \mathrm{~B}$, скорость сильно уменьшается по линейному закону, начиная с самых маленьких напряжений (рис. 16, b). Эффективная валентность тоже ведет себя по-разному (рис. 16,c), оставаясь на уровне $n=2.3-2.4$ для $E=2.5 \mathrm{~B}$ и заметно возрастая от напряжения, до $n=2.8$ для $E=4.5 \mathrm{~B}$.

Аналогичные эксперименты по зависимости от напряжения были проведены в темноте при $E=0 \mathrm{~B}$ (см. табл. 4). Морфология пор (картинка не приводится) остается характерной для пробоя в темноте, схожей с полученной при $U=10 \mathrm{~B}$ (рис. 5 и $6, E=0 \mathrm{~B}$ ). Проведенные эксперименты показали, что при $U=1 \mathrm{~B}$ между основными каналами образуется много пробойных пор, которые располагаются в горизонтальной плоскости вдоль направлений $\langle 100\rangle$, и никаких длинных наклонных ветвей не появляется. По мере возрастания напряжения плотность основных каналов увеличивается, а сами они становятся тоньше, степень ориентационного порядка для вертикальных пор возрастает. Это сопровождается увеличением пористости и скорости травления, а вот валентность, напротив, уменьшается.

\section{6. Кинетика травления}

Сравнение результатов травления, проводившегося при одинаковом смещении и одинаковой подсветке, но в течение разного времени (табл. 5), указывает, что увеличение длительности процесса приводит к возрастанию пористости, но снижению средней скорости и валентности. Это послужило стимулом к исследованию зависимостей от времени.

Для более детального изучения кинетики процесса порообразования было проведено анодирование с разной длительностью в режиме пробоя при $U=12 \mathrm{~B}$, $E=2.5$ В (табл. 6), и в режиме формирования фотопор при малом смещении $U=1 \mathrm{~B}, E=4.5 \mathrm{~B}$ (табл. 7). При малых напряжениях смещения изменение тока со временем в процессе травления отличается от наблюдаемого в режиме пробоя: ток либо остается неизменным, либо слегка уменьшается (см. рис. 17). Заметим, что оба режима дают близкие значения среднего по времени тока, $I_{\mathrm{av}}=25-26 \mathrm{мA}$, во втором случае за счет более высокой интенсивности подсветки.

Сравнение зависимостей $p, r, n$ и $L$ от времени можно видеть на рис. 18. Из рис. 18, $a$ видно, что для малых времен травления в режиме фотопор пористость выше, чем для пробойного режима, так как анодирование проводилось при большем освещении. Однако по мере возрастания длительности процесса пористость лишь немного увеличивалась, в то время как в пробойном режиме она возрастала в 3.57 раза быстрее. Это происходило за счет новых пор, как боковых, так и идущих с поверхности, вместе с тем в режиме фотопор преобладала реакция на дне основных каналов. Валентность в режиме фотопор оставалась почти неизменной на

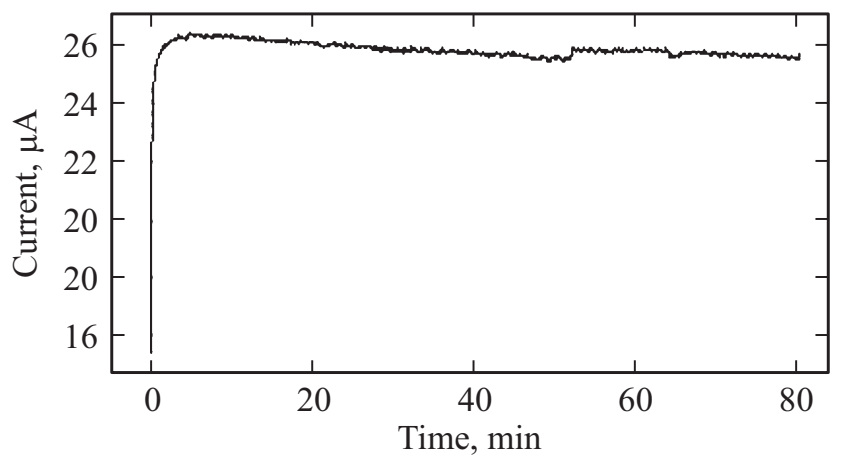

Рис. 17. Зависимость тока травления от времени при низком напряжении, $U=1 \mathrm{~B}$, и подсветке с $E=4.5 \mathrm{~B}$ (режим фотопор). 

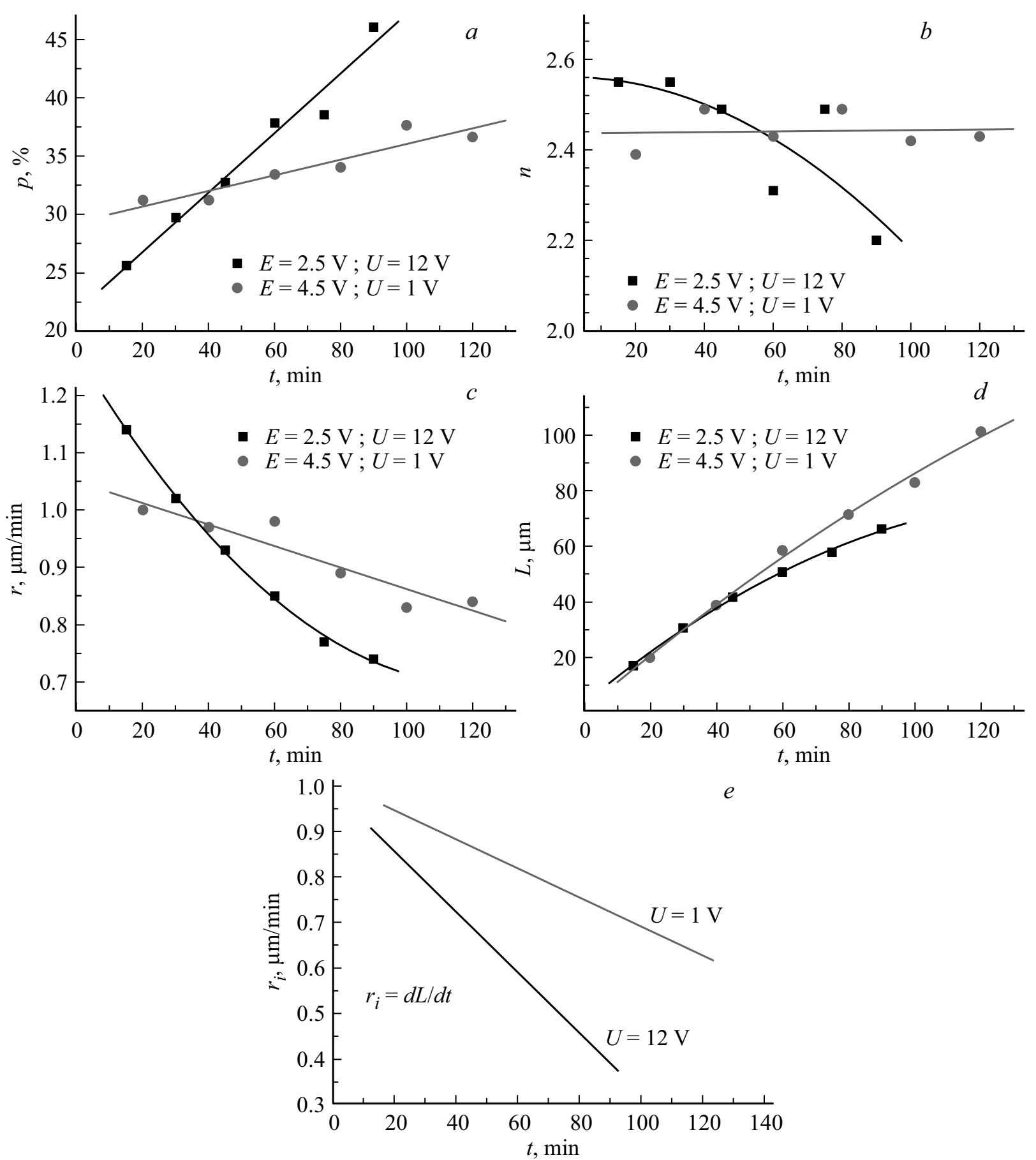

Рис. 18. Зависимости от времени для пробойного режима травления $(U=12 \mathrm{~B})$ и травления в режиме нормальных фотопор $(U=1 \mathrm{~B}): a-$ пористость, $b-$ эффективная валентность, $c-$ средняя скорость травления, $d-$ глубина пористого слоя, $e-$ мгновенная скорость травления $r_{i}=d L / d t$.

уровне $n=2.44$, а для пробойного режима обнаруживала тенденцию к снижению (рис. 18,b). Для малых длительностей средняя скорость $r$ в пробойном режиме была выше, чем в случае фотопор, несмотря на меньшую интенсивность подсветки, но спад ее происходил быстpee (рис. $18, c)$. Для определения мгновенной скорости $r_{i}$ осуществлялось дифференцирование функций второго порядка, аппроксимирующих зависимости глубины от времени в обоих режимах (рис. 18, $d$ ). Полученные зависимости $r_{i}(t)$ приведены на рис. 18, e. Уменьшение мгновенной скорости со временем в пробойном режиме происходит в 1.85 раза быстрее, чем в режиме фотопор. На рис. 19 показано, как изменяется со временем морфология пор в верхней части структуры, полученной в режиме пробоя. Видно, что появляются новые каналы, зарождающиеся на поверхности, и увеличивается коли- 


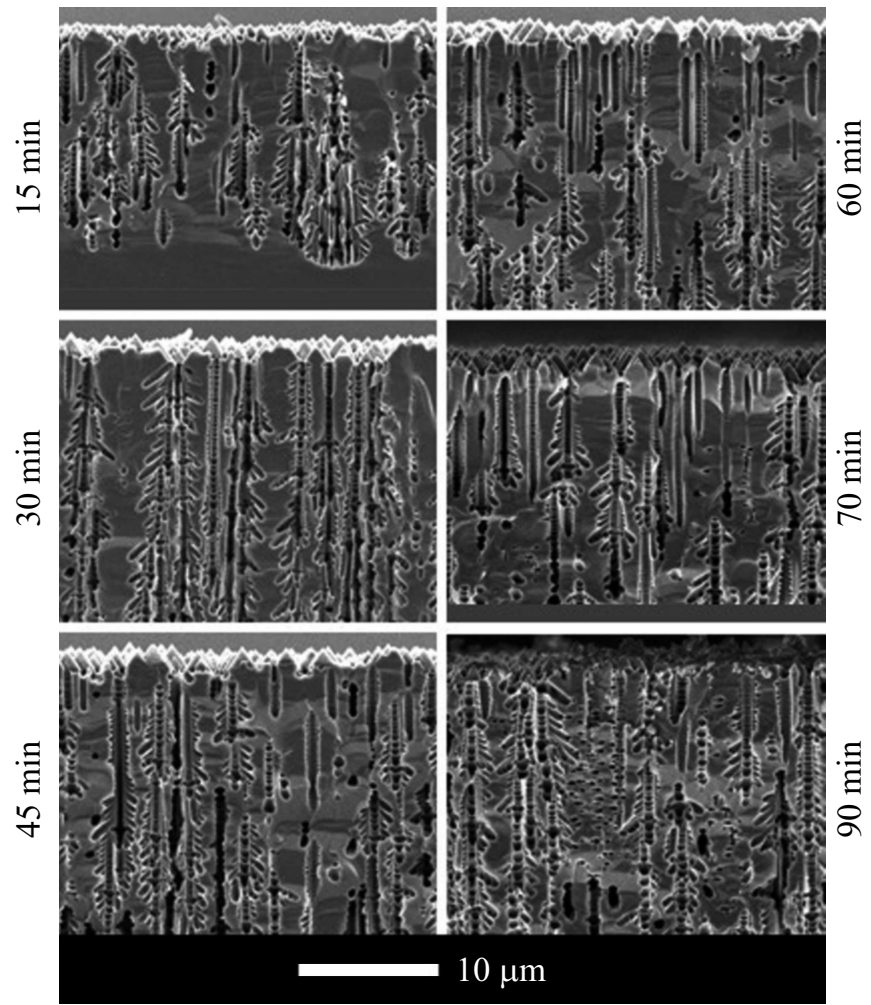

Рис. 19. Изображение верхней части пористой структуры, сформировавшейся при разной длительности травления в пробойном режиме, $U=12 \mathrm{~B}, E=2.5 \mathrm{~B}$.

чество вторичных пор. По-видимому, их появление и приводит к наблюдаемому возрастанию тока от времени (рис. 4, $a$ ). Среднее расстояние между основными каналами уменьшается от $a=3.31$ мкм при $t=15$ мин до $a=1.57$ мкм при $t=90$ мин. Здесь же можно видеть, как происходит умножение пор с глубиной (рис. 19, $t=15$ мин). В режиме фотопор характер структуры остается почти неизменным (не показан), происходит только увеличение глубины и диаметра каналов.

\section{7. Переход из одного режима травления в другой}

Управлять режимом в процессе травления можно, изменяя интенсивность подсветки или изменяя смещение на границе кремний-электролит. На рис. 20, $a$ представлен режим травления, при котором подсветка линейно возрастала в течение 140 мин от $E=0$ до 6 В. Через каждые 13 мин напряжение от $U=12$ В ступенчато снижалось до $0.5 \mathrm{~B}$ и сохранялось таковым в течение 7 мин, формируя метки на пористой структуре. В левой части рис. 20, $b$ приведено изображение поперечного сечения сформировавшейся пористой структуры, где хорошо видно 7 периодов, соответствующих изменению напряжения. В правой части рисунка показано увеличенное изображение пор, соответствующих 2-му и 6-му периодам. Видно, что малая подсветка в пробойном режиме приводит к формированию коротких преимущественно горизонтально ориентированных боковых пор (период 2), а высокая интенсивность подсветки позволяет видеть переход от наклонных пробойных пор при $U=12 \mathrm{~B}$ к, „хорошим“ фотопорам при $U=0.5 \mathrm{~B}$. Обращает на себя внимание следующий факт: несмотря на то что длительность пробойной фазы травления почти в 2 раза больше, чем фазы фотопор, длины соответствующих каналов близки друг к другу. Это согласуется с результатами предыдущих экспериментов, из которых следует, что появление ветвления и присущей ему повышенной пористости приводит к снижению скорости продвижения фронта в глубь подложки.

Аналогичный эксперимент был проведен с образцом 20-03-N2. В этом случае плавно возрастало смещение от $U=0$ до $20 \mathrm{~B}$, а подсветка менялась ступенчато с периодом 20 мин от $E=2 \mathrm{~B}(t=13$ мин) до $6 \mathrm{~B}$ $(t=7$ мин) (рис. 21, $a)$. SEM-изображение полученной структуры показано на рис. $21, b$. Здесь тоже хорошо видно 7 периодов, каждый из которых заканчивается образованием полости, соответствующей переходу к режиму электрополировки за счет ступенчатого увеличения интенсивности света, а также заметно уменьшение скорости травления с глубиной.

\section{8. Обсуждение результатов}

Электролиты на основе органических растворителей имеют более низкое значение диэлектрической проницаемости $\varepsilon$ и существенно более высокое удельное сопротивление $\rho_{\mathrm{el}}$, по сравнению с водными электролитами. Для ДМФ $\varepsilon=36.7$, а $4 \%$-й раствор НF в ДМФ имеет $\rho_{\mathrm{el}}=7.4 \cdot 10^{3} \mathrm{OM} \cdot \mathrm{cm}[4]$. Несмотря на то что органические растворы содержат некоторое количество воды, привнесенное при добавлении плавиковой кислоты, степень диссоциации молекулы плавиковой кислоты в них ниже, чем в водных растворах. Это уменышает концентрацию активных ионов, адсорбированных на поверхности полупроводника. Органические растворы HF обладают низкой окислительной способностью, в результате образование оксида кремния при анодировании сильно подавлено и превалирует прямое растворение кремния [12]. Важным фактором, влияющим на образование пор, является пассивация поверхности полупроводника, т. е. способность насытить поверхностные связи водородом и удалить состояния в запрещенной зоне на границе с электролитом. Водородная пассивация различается для плоскостей с разной кристаллографической ориентацией и определяет преимущественное направление роста пор. Органические электролиты обладают низкой способностью к пассивации из-за медленной адсорбции водорода, которая легко нарушается, что и приводит к появлению боковых пор [12].

Как известно, при анодировании кремния $n$-типа проводимости в растворах HF граница кремний-электролит оказывается при обратном смещении и через нее протекает чрезвычайно малый ток. Для начала травления в 


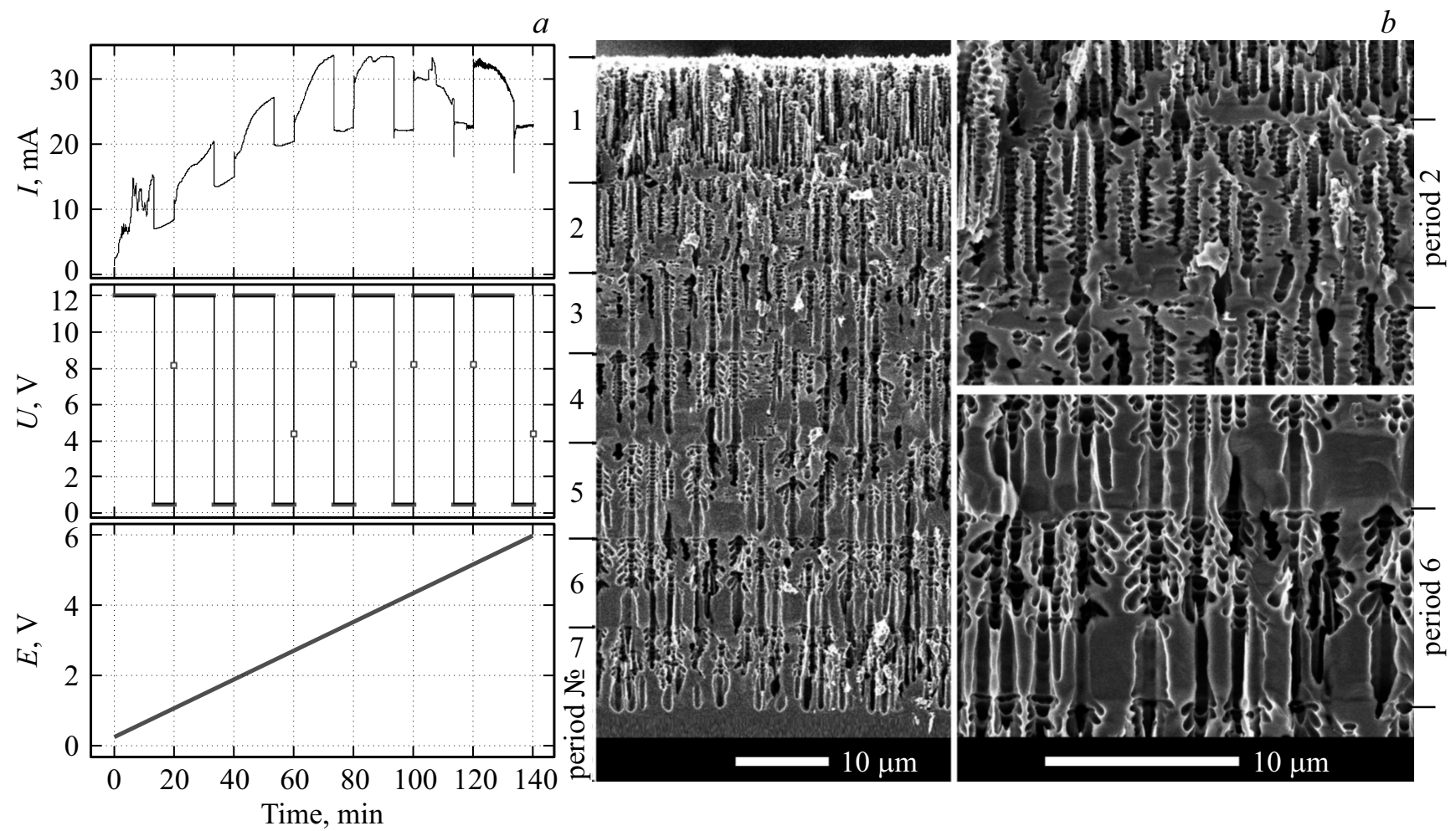

Рис. 20. Режим травления образца 20-03-N1 с плавно возрастающей интенсивностью подсветки и периодически изменяющимся смещением $(a)$ и структура образца $(b)$.

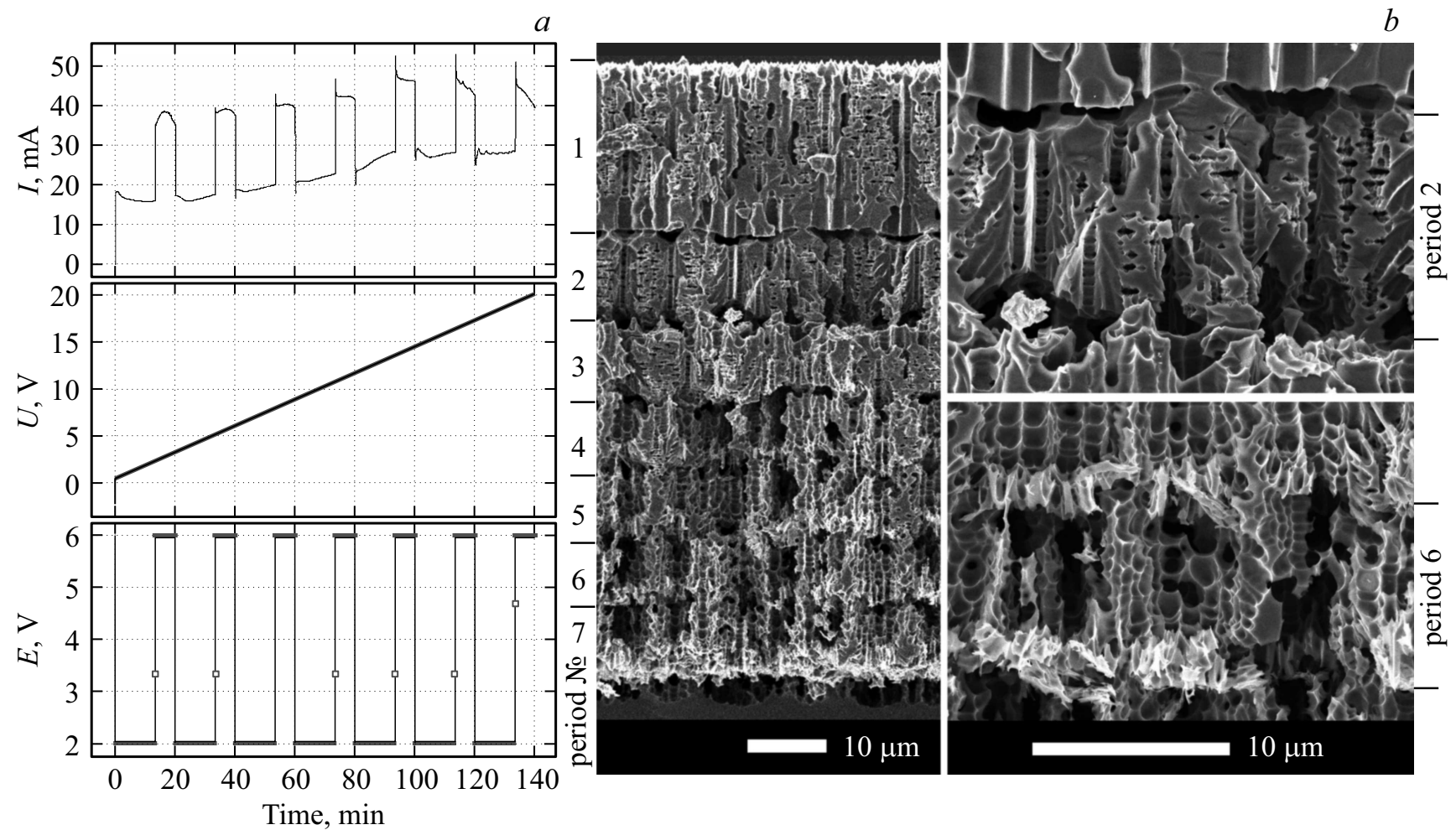

Рис. 21. Режим травления образца 20-03-N2 с плавно возрастающим напряжением и периодически изменяющейся подсветкой $(a)$ и структура образца $(b)$. 
материале со средним или малым уровнем легирования необходимо, чтобы в кремнии появились свободные носители заряда (дырки). Эти носители могут генерироваться при освещении обратной стороны образца собственным светом или за счет пробоя в слое объемного заряда (CO3), лавинного или туннельного [2,12-14]. В отличие от твердотельных приборов, где пробой приводит к протеканию больших токов и может привести к локальному нагреву и разрушению, ток в электрохимической ячейке всегда ограничен массопереносом реактивов в электролите или кинетикой реакции. Концентрация носителей заряда и скорость их поступления в зону реакции зависят от напряженности электрического поля. Если радиус кривизны в области интерфейса близок или меньше, чем ширина СО3 для плоской поверхности, то в этом месте происходит увеличение напряженности электрического поля [2,8]. Для нашего материала ширина слоя объемного заряда, соответствующая плоской поверхности, составляет 0.9 мкм при $U=1$ В и 2.5 мкм при $U=10 \mathrm{~B}[16]$, а радиус фотопор при малых напряжениях $R \approx 1$ мкм (см. рис. $12, b)$. Поэтому можно ожидать, что с ростом напряжения, приложенного к интерфейсу, происходит увеличение напряженности поля в СО3. Увеличение тока через межфазную границу, которое мы называем пробоем, может быть обусловлено не обязательно электрическим пробоем в СОЗ. Важнейшую роль в порообразовании играет распределение потенциала, падающего на слоях, граничащих с интерфейсом. Если происходит реакция прямого растворения $\mathrm{Si}$ (без фазы образования окисла) [12], то внешнее напряжение $U$ распределяется между CO3, $\Delta U_{S C}$, и слоем Гельмгольца, $\Delta U_{\mathrm{H}}$. Падение напряжения в кремнии и в объеме электролита в нашем случае можно не учитывать, так как, согласно схеме измерений, регистрируется потенциал непосредственно на межфазной границе у поверхности. При росте напряжения изгиб зон на границе кремнийэлектролит возрастает, что может приводить к инверсии и вырождению. Образовавшийся инверсный $p^{+}$-слой экранирует СО3 полупроводника, и весь приложенный потенциал падает в слое Гельмгольца. В какой-то момент достигается пороговое значение $\Delta U_{\mathrm{H}}$, при котором начинается реакция порообразования [10].

Как следует из проведенных экспериментов, можно выделить 2 режима фотоанодирования в растворе ДМФ: режим, условно называемый пробоем, которому присуще интенсивное образование вторичных пор, и режим фотопор, когда каналы имеют вертикальные стенки, шероховатость которых уменьшается с ростом подсветки. Для наших кремния и электролита переход между этими двумя режимами происходит в интервале $U=2-4 \mathrm{~B}$. При фототравлении в пробойном режиме образуется 3 типа пор: это основные каналы, направленные вертикально по направлению $\langle 100\rangle$, и вторичные поры двух видов - поры меньшего диаметра, растущие в горизонтальной плоскости вдоль осей $\langle 100\rangle$ (пробойные поры), и наклонные ветви, распространяющиеся в направлении $\langle 111\rangle$. В отличие от работы [11], где авторы считают, что при травлении $n$-Si в ДМФ происходит образование

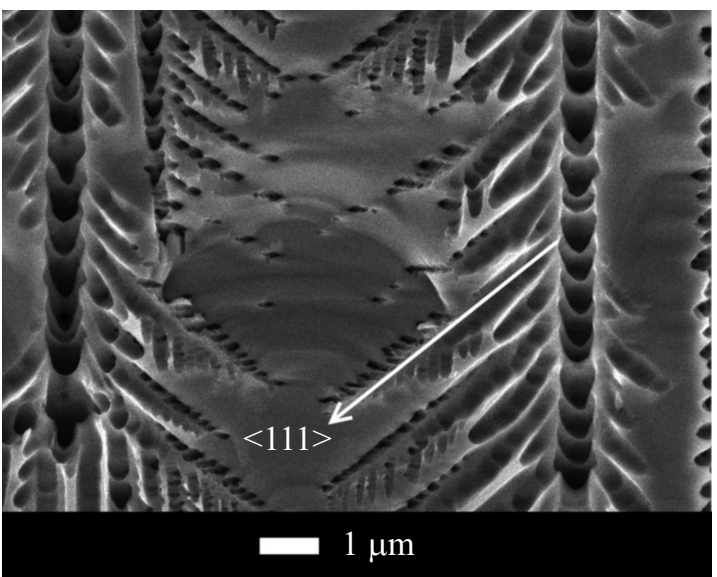

Рис. 22. Отверстия, образованные пробойными порами, исходящими из наклонных ветвей.

двумерной полости с потолком, представляющим собой плоскость (111), в наших экспериментах мы видим образование не полостей, а длинных боковых пор. Эти наклонные боковые поры тоже подвержены ветвлению, и из них исходят пробойные поры, распространяющиеся вдоль направлений $\langle 100\rangle$, как в вертикальной, так и в горизонтальной плоскости. В этом случае их можно рассматривать уже не как вторичные, а как поры третьего уровня, т.е. формируется фрактальная структура. В плоскости сечения соответствующие пробойным порам отверстия выстраиваются в линии вдоль направления $\langle 111\rangle$ на расстоянии $\sim 200$ нм друг от друга (см. рис. 22).

Наблюдаемое ветвление связано с нарушением пассивации стенок пор из-за пробоя в слое Гельмгольца. Анизотропия, которая выражается в ориентации вторичных и третичных пор вдоль кристаллографических направлений $\langle 100\rangle$ и $\langle 111\rangle$, присуща малой интенсивности подсветки. При большей интенсивности поры приобретают все более округлые формы, т.е. анизотропия снижается. В соответствии с классификацией Феля [13], при малой интенсивности света мы наблюдаем формирование crysto-пор, причем внутри этого режима существует переход от crysto- $\langle 100\rangle$ к crysto- $\langle 111\rangle$. Это явление противоречит тезису о том, что плоскости (111) наилучшим образом пассивированы и поэтому рост пор в этом направлении не происходит. Роль подсветки сводится к переключению части тока к донной части пор. Конкуренция процессов, происходящих на дне пор, с таковыми на боковых стенках приводит к тому, что ветвление подавляется и при достаточно интенсивной подсветке, $E=4.5 \mathrm{~B}$, и низком напряжении $U=1 \mathrm{~B}$, формируются цилиндрические фотопоры с гладкими стенками (рис. 15 и 23). Обращает на себя внимание сильно выраженная зависимость морфологии пор от глубины (см. рис. 6 и 11). Это свидетельствует о том, что верхняя часть и концы пор находятся при разном смещении за счет высокого удельного сопротивления электролита. 


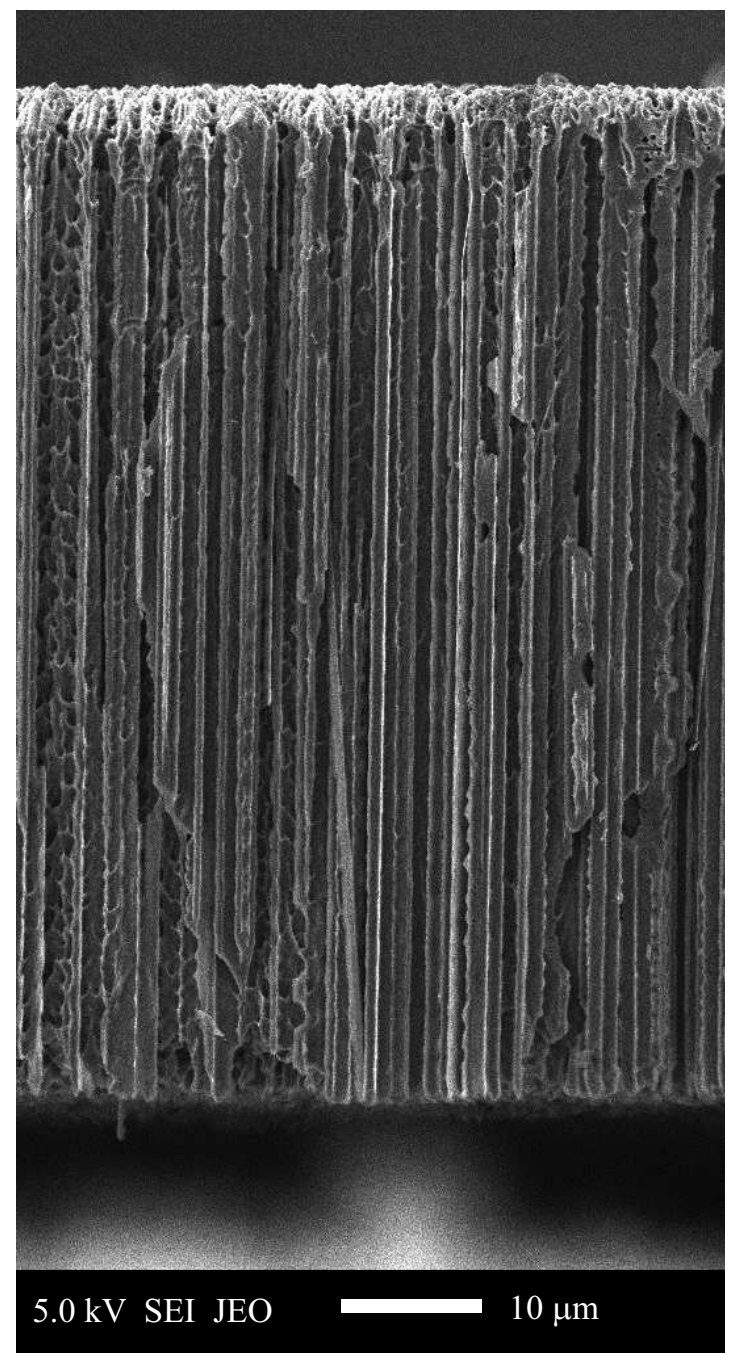

Рис. 23. Макропористая мембрана, полученная в результате травления при $U=4 \mathrm{~B}, E=4 \mathrm{~B}$ (80 мин) и 30 -минутного отделения при $E=6 \mathrm{~B}$.

Обсудим влияние света на скорость травления в режиме пробоя (рис. 9, $)$ ). До $E=2.5 \mathrm{~B}$, т. е. до появления расслоения, связанного с временны́м переходом в режим локальной электрополировки, скорость по мере увеличения подсветки возрастает. При большей интенсивности света когда кроме образования пустот внутри пористого слоя происходит отделение мембраны от подложки, скорость сильно падает. Аналогичная картина наблюдается и на зависимости от напряжения (рис. 13, b). Здесь спадающий участок при $U>2$ В связан с перераспределением тока в пользу боковых пор. Ветвление и увеличение плотности основных каналов приводят к росту пористости, результатом которого является замедление движения фронта вглубь. На зависимостях пористости от напряжения для двух разных подсветок (рис. 16,a) этому соответствует перелом на кривых при $U=4$ В. Отметим, что похожее явление, которое заключается в самопроизвольном переходе из режима электрополировки в режим curro-пор с образованием слоистой структуры, наблюдалось в работе [17] при травлении без подсветки.

Следует обратить внимание на то, что в ряде экспериментов мы получили эффективную валентность $n<2$. Это происходило в пробойном режиме при анодировании в темноте (табл. 4) или при малой подсветке $E<1.5$ В (табл. 1 и рис. 9, $d$ ). При среднем уровне освещения, $E=2.5 \mathrm{~B}$, опять же в области пробоя валентность снижалась по мере увеличения напряжения (рис. 16,c) или длительности процесса травления (рис. 18, $b$ ). Такое поведение можно объяснить вкладом чисто химического растворения кремния в ДМФ-электролите, ранее наблюдавшегося нами [6]. Действительно, пробойный режим характеризуется структурой с повышенной пористостью и соответственно хорошо развитой поверхностью, что увеличивает вклад химической составляющей в процесс растворения $\mathrm{Si}$. При высокой интенсивности света, $E=4.5 \mathrm{~B}$, вклад химического травления несуществен по сравнению с электрохимическим. В этом режиме на зависимости валентности от напряжения (рис. 16,c) видно возрастание валентности. Оно происходит за счет приближения к электрополировке, для которой $n=4$.

Для объяснения наших результатов можно предположить, что при анодировании в темноте происходит электрический пробой в СОЗ. Включение света при низких напряжениях, $U<2 \mathrm{~B}$, создает хорошо известный режим травления фотопор, при котором повышенная напряженность поля в СО3 на дне поры фокусирует дырки и обеспечивает рост пор вглубь. При больших напряжениях скачкообразно происходит перераспределение потенциала, который теперь сосредоточен преимущественно в слое Гельмгольца. В этом „пробойном“ режиме изменяется механизм фототравления.

Полученные закономерности позволили определить режим травления, при котором была сформирована макропористая мембрана толщиной 76 мкм с пористостью $52.1 \%$. Для отделения ее от подложки использовалось увеличение интенсивности света в конце процесса. Морфология полученной структуры, состоящей из плотно стоящих вертикальных каналов с периодом $\sim 1$ мкм, показана на рис. 23. Для гексагональной решетки толщину стенок между порами $w$ можно определить, зная пористость и период решетки, $w=a(1-1.05 \sqrt{p})$. Оценки показывают, что средняя толщина стенок между порами в нашей мембране составляет $w \approx 242$ нм. Мембраны с такими тонкими стенками представляют практический интерес, например, для изготовления анодов Li-ионных аккумуляторов, где скорость деградации зависит от толщины стенок Si макропористой структуры [18].

\section{9. Заключение}

Исследование процесса анодирования $n$-Si в 4\%-м растворе НF в ДМФ в условиях подсветки с обратной стороны показало, что образование макропор в органическом электролите существенно отличается от порообразования в водных электролитах. Это прежде всего 
усиленное ветвление основных каналов и их выраженная анизотропия в режиме пробоя при малой интенсивности подсветки, скачкообразный переход из режима обычных фотопор с вертикальными стенками в режим пробоя при напряжении $U=2-4 \mathrm{~B}$, а также более высокая пористость по сравнению с водными электролитами той же концентрации НF. При травлении в ДМФ при малых напряжениях не наблюдается образования бочкообразных макропор большого диаметра, как это происходит в электролитах на основе $\mathrm{H}_{2} \mathrm{O}[2,19]$. Электролиту на основе ДМФ присуще замедление скорости распространения фронта вглубь, особенно сильно выраженное при травлении в режиме пробоя. Высокое напряжение, приложенное к интерфейсу, облегчает переход в режим электрополировки, который наступает раньше и на меньшей глубине. Обнаружена необычная морфология со вторичными порами, растущими вдоль кристалло-

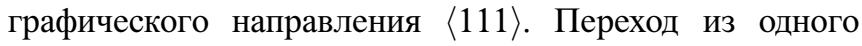
режима травления в другой - из обычного в пробойный и от порооборазования к электрополировке - может быть осуществлен в ходе анодирования путем изменения напряжения или интенсивности света. Показано, что при использовании электролита на основе ДМФ можно получать макропористые слои с высокой пористостью, не присущей макропорам, сформированным при тех же условиях в водных электролитах, и легко отделять их от подложки.

Работа выполнена с использованием оборудования центра коллективного пользования „Материаловедение и диагностика в передовых технологиях“. Авторы выражают искреннюю признательность В.П. Улину за ознакомление с рукописью и полезное обсуждение, а также Д.В. Жилиной за предоставление текстурированных пластин.

\section{Список литературы}

[1] V. Lehmann, H. Foll. J. Electrochem. Soc., 137, 653 (1990).

[2] V. Lehmann. Electrochemistry of Silicon (Weinheim, Wiley-VCH, 2002) p. 183.

[3] J.-N. Chazalviel, F. Ozanam. In: Ordered Porous Nanostructures and Applications, ed. by R.B. Wehrspohn (N.Y., Springer Science+Business Media, Inc., 2005) p. 15.

[4] E.V. Astrova, T.N. Borovinskaya, A.V. Tkachenko, S. Balakrishnan, T.S. Perova, A. Rafferty, Y.K. Gun'ko. J. Micromech. Microeng., 14, 1022 (2004).

[5] M. Christophersen, J. Carstensen, H. Foll. Phys. Status Solidi A, 182, 103 (2000).

[6] Н.Е. Преображенский, Е.В. Астрова, С.И. Павлов, В.Б. Воронков, А.М. Румянцев, В.В. Жданов. ФТП, 51 (1), 79 (2017).

[7] N. Gabouze, F. Ozanahm. In: Handbook of Porous Silicon, ed. by L. Canham (Switzerland, Springer Intern. Pub., 2014) p. 103.

[8] X.G. Zhang. J. Electrochem. Soc., 151 (1), C69 (2004).

[9] K.W. Kolasinski. Sur. Sci., 603, 1904 (2009).

[10] В.П. Улин, Н.В. Улин, Ф.Ю. Солдатенков. ФТП, 51 (4), 481 (2017).
[11] M. Christophersen, J. Carstensen, H. Foll. Phys. Status Solidi A, 182, 601 (2000).

[12] H. Foll, M. Christophersen, J. Carstensen, G. Haase. Mater. Sci. Eng. R, 39, 93 (2002).

[13] H. Foll, M. Leisner, A. Cojocaru, J. Carstensen. Materials, 3, 3006 (2010).

[14] V. Lehmann, R. Stengl, A. Luigart. Mater. Sci. Eng. B, 69/70, 11 (2000).

[15] E.V. Astrova, G.V. Fedulova. J. Micromech. Microeng., 19, 095009 (2009).

[16] С. Зи. Физика полупроводниковых приборов (М., Мир, 1984) кн. 1, с. 85.

[17] S. Frey, M. Kemell, J. Carstensen, S. Langa, H. Föll. Phys. Status Solidi A, 202, 1369 (2005).

[18] Г.В. Ли, Е.В. Астрова, А.М. Румянцев, В.Б. Воронков, А.В. Парфеньева, В.А. Толмачев, Т.Л. Кулова, А.М. Скундин. Электрохимия, 51 (10), 1020 (2015).

[19] V. Lehmann. J. Electrochem. Soc., 140 (10), 283 (1993).

Редактор Л.В. Шаронова

\section{Formation of macropores in $n-S i$ under anodization in organic electrolyte}

E.V. Astrova, N.E. Preobrazhenskiy, G.V. Li, S.I. Pavlov

loffe Institute,

194021 St. Petersburg, Russia

Abstract An experimental study of photoelectrochemical etching of solar grade electron silicon in the $4 \%$ solution of $\mathrm{HF}$ in dimethylformamide has been carried out. The morphology of the pores, porosity, effective valence and etching rate were studied depending on the applied voltage, illumination intensity of the sample back side and the duration of the process. It has been found that the anodization laws of $n$-Si in the organic electrolyte differ substantially from those for aqueous solutions. This appeares in the fact that at a voltage above the threshold, in the so-called breakdown mode, macropores with vertical walls begin to multiply and branch intensively due to the appearance of side pores. The rise of the secondary pores is accompanied by an increase in porosity, a decrease in the propagation rate of the porous deep into the substrate, and a rapid transition to the electropolishing regime. In the breakdown mode, at a low illumination level, a fractal structure of macropores propagating along certain crystallographic directions was directed: $\langle 100\rangle$ and $\langle 111\rangle$, the letter effect was not observed previously. It is demonstrated that the morphology of macropores can be controlled during the anodizing process by transition from one mode to another when changing external parameters: voltage or illumination. It has been shown that application of the organic electrolyte enables to obtain macroporous membrans with a porosity, much higher than porosity of those formed in aqueous electrolytes under the same conditions. 